\title{
Prácticas de RSE en cooperativas. Experiencias y resultados mediante el estudio de casos
}

\author{
Francisco Javier Pérez-Sanz \\ Ana F. Gargallo-Castel \\ M. Luisa Esteban-Salvador
}

RESUMEN: La conducta observada en las organizaciones que conforman el entramado de la Economía Social ha supuesto un precedente en actuaciones y prácticas que representan una forma de hacer empresa basada en la responsabilidad social, incluidas sus múltiples acepciones y enfoques. Asimismo, se percibe un creciente interés en la llamada Responsabilidad Social de la Empresa (RSE), un modelo de gestión implantado en diversos tipos de organizaciones, con y sin fines lucrativos, que lleva consigo el compromiso con un conjunto de valores ligados a todos sus grupos de interés. En el marco de la Economía Social, las cooperativas operan en conformidad con los criterios, valores y principios de RSE, interés por la comunidad y servicio a sus miembros, no solamente en la esfera económica, sino también en el ámbito social y medioambiental. Múltiples trabajos manifiestan la concordancia entre el desarrollo de las políticas de RSE en sus tres vertientes (económica, social y ambiental) y los valores y principios cooperativos enunciados por la Alianza Cooperativa Internacional ( $\mathrm{ACl}, 1995)$. Estos estudios avalan la afirmación de que la propia naturaleza de las cooperativas implica un comportamiento socialmente responsable. Asumidos estos postulados, el objetivo del presente trabajo es observar y constatar el cumplimiento efectivo de los mismos en cooperativas de diferentes sectores y entornos, cuestión que conlleva el análisis de la gestión integral de las actuaciones inherentes de RSE, derivadas de sus relaciones con los distintos agentes, según la Teoría de los grupos de interés (Turker, 2009). Adicionalmente, las cooperativas deben buscar la supervivencia mediante sus resultados económicos plasmados en la obtención de unos excedentes y una rentabilidad adecuados (López y Marcuello, 2006), con la finalidad de prestar servicios a los socios a lo largo del tiempo, y todo ello en sintonía con las demandas de los distintos grupos de interés. Por estos motivos, el estudio contrasta la aplicación de la RSE con la obtención de resultados económicos en un entorno de crisis económica. Mediante una metodología de estudio de casos, se han seleccionado seis cooperativas españolas pertenecientes a diversos sectores, para analizar sus memorias y cuentas de resultados, con el objeto de identificar relaciones entre sus comportamientos de RSE y los resultados económico-financieros obtenidos en un periodo de tiempo determinado.

PALABRAS CLAVE: Responsabilidad Social Empresarial, Economía Social, Cooperativas, Grupos de interés, Memorias de Sostenibilidad, Rentabilidad.

CLAVES ECONLIT: M19, M14, P13, L29.

Cómo citar este artículo / How to cite this article: PÉREZ-SANZ, F.J., GARGALLO CASTEL, A.F. \& ESTEBAN-

SALVADOR, M.L. (2019): "Prácticas de RSE en cooperativas. Experiencias y resultados mediante el estudio de casos", CIRIEC-España, Revista de Economía Pública, Social y Cooperativa, 97, 137-178. DOI: 10.7203/CIRIEC-E.97.11043.

Correspondencia: Francisco Javier Pérez-Sanz, Ana F. Gargallo-Castel y M. Luisa Esteban-Salvador, Facultad de Ciencias Sociales y Humanas, Universidad de Zaragoza - Campus de Teruel.

E-mail de contacto: fjperez@unizar.es. 


\section{EXPANDED ABSTRACT}

\section{CSR practices among co-operatives. Experience and results of case studies}

The behaviour observed in the organizations of the Social Economy framework has set a precedent in business practices which are based on social responsibility. There is also a growing interest in so-called Corporate Social Responsibility (CSR), a management model implemented in different types of for- and non-profit organizations, which entails a commitment to a set of values linked to all its stakeholders.

Within the framework of the Social Economy, cooperatives operate under the criteria, values, and principles of CSR. They have an interest in the community and in providing service to their members, not only economically but also socially and environmentally. There is a body of evidence which shows the link between the development of CSR policies (economic, social and environmental) and the cooperative values and principles laid out by the International Cooperative Alliance (ICA, 1995). These studies support the claim that the very nature of cooperatives implies socially responsible behaviour.

In the last two decades, and more intensely during the recent economic crisis, Spanish cooperatives have shown an increasing interest in the development of CSR policies through concrete actions (Monzón and Antuñano, 2012). Likewise, cooperatives seek to broaden the communication channels with their stakeholders and with society as a whole, through the preparation of well-defined and accessible CSR reports, as an additional element of transparency in their management model.

In light of the above, the general objective of this study is to observe and verify the effective CSR compliance in a scenario of economic crisis across cooperatives from different sectors and environments. This issue entails the analysis of the management of CSR actions, derived from the relations with the relevant agents, according to the Theory of Stakeholders (Turker, 2009). This is linked to the nature of cooperatives and their operating principles given their afore-posited predisposition to more effective CSR implementation in comparison to other business formulas (Bel and Marín, 2008; Sanchís and Rodríguez, 2018). This facet goes hand in hand with a marked interest in transparency, accountability and the preparation of SCR reports as a way of transmitting their differentiating characteristics to their interest groups (Gallardo and Castilla, 2015).

In addition, the economic literature on the subject recognises CSR as a fundamental resource for creating a competitive advantage applicable to cooperatives. These organizations develop strategies that allow them to survive thanks to their economic results, reflected in the obtaining of adequate surpluses (López and Marcuello, 2006), by the aim of providing services to members over time, and all in tune with the demands of the different interest groups. For these reasons, the second objective of the 
study is to contrast the CSR implementation with profit generation in these entities, in a context of economic crisis, and to seek certainties on the alignment between the social and economic function of the cooperatives (Gallardo and Castilla, 2015).

Following Villareal and Landeta (2010), a case study methodology has been applied. For this, we have selected six Spanish cooperatives from different sectors with a high degree of significance within the Ranking "Relevant Companies of the Social Economy" 2010-2011 published by the Social Economy Business Confederation (CEPES). Subsequently, the chosen cooperatives have been refined and sorted based on the available documentation. For this, first all the potentially comparable information regarding the development of CSR actions has been collected. Then, the available financial data have been obtained. In parallel, qualitative and quantitative information of these cooperatives has been extracted from the publications of CSR and economic reports. These data have been complemented with information from other secondary sources.

Consequently, the relevant CSR factors relating to the social, economic and environmental dimensions have been determined according to the RSECOOP model (2011) following the indicators of the Global Reporting Initiative. Then, the economic-financial ratios have been selected, which reveal positions in accordance with the different interest groups of the selected cooperatives.

Next, we start from the hypothesis, widely reviewed in the literature, which associates cooperative principles with behaviours consistent with the development of social responsibility towards stakeholders, and considers that these organisations should integrate these behaviours into their management policies (Server and Capo, 2009). This issue is closely related to the creation of added (Mozas, 2010) and the obtaining of lasting competitive advantages (Castilla et al., 2015). Thus, under the stated objectives, a basic evaluation of compliance with the relevant CSR factors for these six cooperatives is first carried out (COCETA, 2001). To this end, the results obtained are verified and compared using the numerical values offered and are grouped into charts for better visualization of the degree of compliance (concentration-dispersion) with the CSR in the three vectors considered. Then, the CSR values obtained are contrasted with the average values of the profitability ratios applied for these cooperatives, to observe possible relationships between compliance with the CSR variables and the economic results of the organizations.

After analyzing the CSR practices developed by the cooperatives under study, relatively high compliance with socially responsible behaviours has been observed, since the results show positive values and highly homogeneous deviations.

However, not all cases denote a development of CSR according to the relative position of the cooperative in the market and its economic results. Therefore, a degree of commitment to its stakeholders based on the specific corporate culture and values present is perceived. On the other hand, certain biases in the configuration of the CSR have been observed as an integral business management model, 
since not all CSR vectors have been observed with the same intensity in each of the cases. Also, there is a correlation in the cooperatives between the economic results obtained, measured in terms of commercial margin, and the overall development of CSR practices. It is reflected more intensely in the economic profitability ratios and corresponds to the progress of social responsibility aspects in the economic vector. Finally, the results obtained could serve, in general, to strengthen the theory, generally accepted in the literature about the capacity of cooperatives to be more resistant in crisis environments by promoting a more socially responsible economy. However, it is still necessary for these organizations to make greater efforts to communicate their social performance and the advantages of the CSR's reported management as a tool for competing in markets.

One of the limitations of the study derives from the difficulty of configuring and examining a large number of variables. This leads to a reduced case study, which prevents, due to the size of the sample, the establishment and/or modelling of causal relationships for Spanish cooperatives in the reference period as a whole. Nevertheless, this issue has not been the object of analysis, as justified in the design of the study. We must also add the limitation of not having homogeneous and constant information for all cooperatives or more extended periods.

The contribution of this research is reflected firstly in the particularities that can be approached in greater depth from the analysis of specific cases, reviewing social and economic behaviour of cooperatives. And secondly, the proposed methodology can be used as a guide to be adapted and expanded to analyze this type of relationship in different contexts and scenarios. For example, the study can be replicated to analyze cooperatives from the same sector or to carry out cross-sector comparisons. Future research can consider specific geographical areas and different periods, with varying dimensions and sizes, or even ultimately, the model may allow comparisons with other companies that are not part of the Social Economy.

KEYWORDS: Corporate Social Responsibility, Social Economy, Cooperatives, Stakeholders, Sustainability Reports, Profitability, Performance. 


\section{Introducción 1}

El concepto de Responsabilidad Social de la Empresa (en adelante RSE) puede ser analizado desde diferentes perspectivas económicas, sociales y políticas, a la vez que viene a englobar una serie de dimensiones que pueden ser entendidas bajo distintas acepciones conceptuales según el lugar y el tipo de economía considerado.

Así pues, es necesario señalar que desde los diversos enfoques de gestión de la empresa, el paradigma liberal ha constituido desde los años 80 y 90 del siglo XX un arquetipo donde el objetivo de los propietarios se centraba en la maximización del beneficio en un horizonte temporal de corto plazo, asociando como única finalidad de responsabilidad social empresarial el incremento de los beneficios (Friedman, 1970). Los propios problemas de esta teoría, así como las profundas transformaciones socio-económicas que se han ido intensificando en las últimas décadas (procesos de globalización, cambios tecnológicos, incremento de la competencia, crecimiento de los beneficios y del poder de las empresas, rechazo y contestación social a este poder...) han favorecido la emergencia de un nuevo modelo heterogéneo, no suficientemente definido, pero cada vez más incipiente. Este viene caracterizado por dos aspectos interconectados: por un lado, una mayor atención a todos colectivos que resultan primordiales para el éxito de la empresa (no solo a los propietarios), y por otro, una mayor preocupación paralela por la sostenibilidad económica de la organización a medio y largo plazo (Moreno, 2004; Martínez y Martínez, 2016; Vergara y Ortiz, 2016).

El nuevo paradigma de gobernanza empresarial formulado inicialmente por Freeman (1984), asocia el mantenimiento de los resultados económicos de la empresa a su interacción con los diversos agentes $^{2}$ denominados stakeholders (propietarios-accionistas, clientes, proveedores, empleados, reguladores y agentes de opinión), así como también con el entorno social donde se ubica. En su actuación, la empresa tiene contraídos fuertes compromisos con sus grupos de interés (partes interesadas, públicos afectados...) en función de su relación directa con ellos, que están provocados por razones dominantes generalmente económicas, más que de tipo ético. La dirección estratégica de la empresa debe buscar un equilibrio en la atención de estos grupos, pues de todos obtiene un recurso básico, ya sea tangible o intangible, que interviene en el logro del óptimo desarrollo de la actividad (Fernández y Bajo, 2012). Por otro lado, atendiendo al juego de intereses parciales de los grupos, una adecuada gestión de los mismos puede conducir a un juego cooperativo, contrario al de suma cero, donde todos pueden beneficiarse, si la empresa es capaz de conseguir un equilibrio adecuado en la

1.- Los autores agradecen el apoyo del Gobierno de Aragón (Grupo de Referencia GESES: S28_17R; CREVALOR: S42_17R y CEMBE: S11-17R,), del FEDER (2014-2020) "Construyendo Europa desde Aragón" y del Ministerio de Economía y Competitividad-FEDER (ECO201786305-C4-3-R).

2.- Freeman (1984) identifica a los agentes como grupos o individuos que afectan o pueden afectar al logro de los objetivos de la entidad. 
atención de todos ellos, constituyendo uno de los principios del buen gobierno corporativo (OCDE, 2015; Barrera, 2016).

En las últimas décadas ha surgido una interesante reflexión sobre el papel de las empresas y su responsabilidad en el desarrollo de un modelo de gestión fundamentado en valores que humanicen la empresa y contribuyan a un desarrollo económico, social y ambiental sostenible (Escuela Economía Social, 2012), lo que fomenta un interés creciente en materia de cultura de RSE (Argandoña, 2011).

Esta visión actual de la RSE, propiciada por una serie de cambios, ha constituido un campo de investigación para las empresas que tratan de satisfacer las expectativas de empleados, clientes, socios, accionistas, proveedores y medio ambiente, con el objeto de buscar un desarrollo económico sostenido y mejora de la calidad para todos los grupos de interés, a la vez que se minimizan los efectos negativos que provocan ciertos comportamientos de la organización (Arcas y Briones, 2009). Se ha producido un cambio de modelo, orientado a una concepción Socio-Económica de la empresa, donde el beneficio ya no es el único indicador valido de la eficiencia empresarial, dado que la organización es considerada como un sistema abierto que determina y es determinado por el entorno, y los grupos de interés aportan cambios de mentalidad en sus comportamientos (De la Cuesta, 2005; Vargas y Vaca, 2005; Simancas y Ledesma, 2017).

Junto a estos cambios, deben añadirse una serie de actuaciones que contribuyen a promover la importancia de la RSE en las empresas. En el ámbito internacional destacan el Pacto Mundial de las Naciones Unidas (Global Compact), el Libro Verde de la Comisión Europea "Fomentar un marco para la Responsabilidad Social de las Empresas" (Comisión Europea, 2001), la Declaración Tripartita de Principios sobre las Empresas de la Organización Internacional del Trabajo (OIT), las Comunicaciones de la Comisión Europea en materia de RSE (Comisión Europea, 2011), la "Estrategia renovada de la UE para 2011-2014 sobre la responsabilidad social de las empresas", la norma AA-1000 (Accountability 1000) confeccionada en 1999 y la norma SA-8000 (Social Accontability 8000), del año 1998 y 2011, 0 el Global Reporting Initiative (GRI). Otras iniciativas originadas en el entorno español son el Código Olivencia (Comisión especial para el estudio de un código ético de los consejos de administración de las sociedades, 1998), la Comisión Aldama (Comisión especial para el fomento de la transparencia y seguridad en los mercados y en las sociedades cotizadas, 2003), el Informe de la Comisión de Responsabilidad Social Corporativa de la Asociación Española de Contabilidad y Administración de Empresas (AECA, 2004), el Informe de la Subcomisión del Congreso de los Diputados para potenciar y promover la RSE (Comisión de Trabajo y Asuntos Sociales, 2006), el informe COINTEGRA de Economía Social y Responsabilidad Social Corporativa (Casasola y Saavedra, 2012) o la Estrategia Española de RSE 2014-2020 (Ministerio de Trabajo, Migraciones y Seguridad Social [MEYSS], 2014), así como la publicación de normativas como la Ley 2/2011 de Economía Sostenible, y la Ley 5/2011 de Economía Social para el reconocimiento y visibilidad de las entidades de Economía Social3.

3.- La Confederación Empresarial Española de la Economía Social (CEPES) considera a las organizaciones de Economía Social como precursoras de la RSE al incorporar una democratización interna en su funcionamiento como forma de construir empresas de ciudadanos hacia fuera de la sociedad. https://www.hispacoop.com/home/index.php/features/50-organizacion-cooperativa/economia-social-y-rse (acceso 20/02/2019). 
En esta línea de actuación, las cooperativas han presentado una fórmula de conducta empresarial estrechamente asociada al ámbito de la RSE, basada principalmente en sus principios y valores innatos (Gallardo y Castilla, 2015). Además, la RSE y la ética empresarial están estrechamente vinculadas y unidas a valores como transparencia, honestidad, preocupación por el entorno y las personas... que, aunque no son exclusivos de las organizaciones cooperativas, presentan un fuerte arraigo en el comportamiento de estas sociedades (Aragón, Iturrioz y Narvaiza, 2017; Mozas y Puentes, 2010; Mukherjee y Pyne, 2016). Las cooperativas desarrollan su actividad en base a su identidad y principios cooperativos (ACl, 1995) guiando su actuación bajo una doble perspectiva, por un lado, empresarial (Nilsson, 1996) y por otro de cara a la sociedad, con el objetivo de cubrir conjuntamente las aspiraciones de sus socios propietarios y grupos interesados, como son los trabajadores, la comunidad, el territorio y el medioambiente. $Y$ todo ello en consonancia con el cumplimiento estricto de las normativas que les afectan, la consecución equilibrada de los objetivos económicos, sociales y medioambientales, persiguiendo una actuación ética en sus decisiones empresariales y apostando por una transparencia en su gestión, conductas que entroncan directamente con las directrices de la RSE (Melián, 2006; Chaves y Soler, 2004; Barrera, 2016).

Este comportamiento se ha convertido en una práctica cada vez más generalizada en el territorio español, según recoge el estudio de la Confederación de Cooperativas de Trabajo Asociado (COCETA, 2010), y que hace aumentar el número de acciones destinadas a mantener e impulsar la responsabilidad social cooperativa (RSECOOP, 2007). Estas actuaciones están basadas en dos pilares fundamentales, el reconocimiento de la identidad entre los valores cooperativos y la filosofía de la RSE, y la idoneidad como estrategia de consolidación y crecimiento del proyecto cooperativo.

En el presente trabajo se propone una investigación exploratoria mediante el estudio de casos ${ }^{4}$, donde se plantean como objetivos, primeramente el examen del grado de desarrollo de comportamientos socialmente responsables propios de la RSE en las cooperativas estudiadas, en segundo lugar, la delimitación de los compromisos de RSE y su ejecución mediante indicadores, con el fin de configurar mapas de RSE que denoten un desarrollo homogéneo en los tres ámbitos (económico-social-medioambiental), y en tercer lugar, la identificación de relaciones entre los comportamientos de RSE observados en las cooperativas analizadas y los resultados económico financieros obtenidos por las mismas (Quevedo, 2003; De Quevedo, De la Fuente y Delgado, 2005; Server y Villalonga, 2005; Brio, Fernández y Junquera, 2005; Forética, 2008; Arcas y Briones, 2009; Monzón y Antuñano, 2012).

En un escenario de crisis económica y financiera como lo fue el año 2010, se pretende mostrar la relevancia que adquiere el desarrollo de los distintos componentes de la RSE en cada una de las cooperativas seleccionadas como elemento facilitador de mayor resistencia de estas organizaciones ante la crisis (Campos y Chaves, 2012). Los resultados podrían fortalecer la teoría de que las cooperativas tienen mayor capacidad de resistencia ante la crisis promoviendo una economía

4.- Como se explicará posteriormente, para la selección de casos se aplica un muestreo no probabilístico de conveniencia. 
socialmente más responsable (Leroux, 2012; Organización Internacional de Cooperativas en la Industria y los Servicios [CICOPA], 2014a, 2014b). La selección de los casos se ha llevado a cabo a partir del Ranking de Cooperativas más relevantes publicado por la Confederación Empresarial Española de la Economía Social (CEPES, 2011), realizando una elección de seis entidades, que presentan actuaciones en materia de RSE de acuerdo a los criterios indicados en el apartado de metodología. El trabajo intenta obtener evidencias empíricas en las cooperativas seleccionadas en un entorno de crisis, que fundamenten las bases teóricas donde se establece el compromiso de estas organizaciones, pertenecientes a la Economía Social, en sus relaciones con sus grupos de interés en los vectores de RSE como son el económico, social y medioambiental.

El estudio, se ha estructurado en cuatro secciones: tras la presente introducción, la segunda sección se dedica a la fundamentación del concepto de RSE y su aplicación a las entidades de Economía Social y a las cooperativas; en la tercera sección se abordan las cuestiones metodológicas relativas a la población objeto de estudio, la selección de los casos y las ratios de rentabilidad consideradas; en la cuarta sección se muestran de forma sintética los resultados obtenidos relativos a las perspectivas del estudio; y finalmente en la quinta se recogen las principales conclusiones y nuevas perspectivas de investigación.

\section{Fundamentos y delimitación de la RSE: proyección en la economía social y en las cooperativas}

\subsection{Delimitación teórica y conceptualización de la Responsabilidad Social de la Empresa (RSE)}

La RSE se ha convertido en un concepto central en los debates sobre el rol que deben asumir las empresas en su relación con la sociedad, conteniéndose en el mismo una base normativa práctica y otra descriptiva y de resultados. En su análisis se pueden destacar dos temas interrelacionados y vinculados al campo de estudio de la empresa y la sociedad: por un lado su perspectiva ética, basada en la acción individual y plasmada en el sistema de valores, visiones morales y actitudes; y por otro, sus perspectivas sociológica y política, estrechamente relacionadas con cuestiones de gobierno, empresa, sociedad y otras instituciones sociales, vinculadas todas ellas con teorías de economía, gestión de empresas, estrategia y política de negocios, ciencia política y derecho.

De esta forma las perspectivas fundamentales de la relación empresa-sociedad se centran en una serie de conceptos y modelos que pueden sintetizarse bajo diferentes enfoques (Garriga y Melé, 2004; Toro, 2006) que han venido sustentando el campo de estudio de la Responsabilidad Social Corporativa, como son las Teorías con enfoque instrumental de la RSE (Porter y Kramer, 2002; Linz, 1996; Prahalad 
y Hammond, 2002; y Prahalad, 2002); las teorías centradas en el poder de las corporaciones en la sociedad y el uso responsable de dicho poder en el ámbito político (Paladino y Mohan, 2002), acuñando expresiones definitorias de RSE como la de Carroll (1979): "abarca las expectativas económicas, legales, éticas y filantrópicas de la sociedad en un momento determinado del tiempo"; las teorías integrativas, centradas en la actuación de la empresa para satisfacer las demandas sociales de sus grupos de interés (Teoría de los stakeholders de Freeman, 1984); y las teorías que abordan la responsabilidad ética de las empresas frente a la sociedad basadas en los principios que expresan lo que se debe o no debe hacer y la necesidad de construir una sociedad mejor, destacando el enfoque de la ciudadanía corporativa y el Corporate Social Performance definido por Wood (1991), como una "configuración organizacional de principios de responsabilidad social y procesos de respuesta social, así como también de políticas, programas y resultados observables que se vinculan con las relaciones sociales de una empresa" (p. 693).

Paralelamente, otros enfoques conciben una estrategia social de RSE, directamente conectada con la misión, visión y valores de la empresa que se incorpora en la cadena de producción/servicios y en la cadena de valor, así como en la gestión de las relaciones con los diversos grupos de la empresa (Toro, 2006). La RSE se concibe como estratégica, formando parte esencial de la empresa y con alcance a largo plazo. En este sentido es posible destacar diversos estudios que sustentan que un mayor output social y una creación de valor para la empresa puede obtenerse de un enfoque estratégico más que de uno filantrópico 0 altruista (Burke y Logsdon, 1996; Husted y Allen, 2000 y Husted y De Jesús, 2006).

No obstante, al hacer referencia al concepto de RSE, se puede señalar que no existe una definición única, sino diferentes posicionamientos proporcionados desde diversas instancias, entre otras:

- La consecución de una relación consensuada y equilibrada con todos sus grupos de interés, así como la configuración de vínculos basados en la honradez y transparencia de actuaciones de cara a los accionistas, trabajadores, proveedores, clientes, comunidad y el entorno ecológico (Jáuregui Atondo, 2005)

- "La libre voluntad de la empresa de adoptar el mayor valor posible a sus diferentes grupos de interés" (Moreno, 2004: 13).

- "La integración voluntaria, por parte de las empresas de las preocupaciones sociales y medioambientales en sus operaciones comerciales y en sus relaciones con sus interlocutores" (Comisión Europea, 2001: 7), redefinida en 2011 como: "la responsabilidad de las empresas por su impacto en la sociedad" (Comisión Europea, 2011: 7).

- "La RSE es además del cumplimiento estricto de las obligaciones legales vigentes, la integración voluntaria en su gobierno y gestión, en su estrategia, políticas y procedimientos, de las preocupaciones sociales, laborales, medio ambientales y de respeto a los derechos humanos que surgen de la relación y el dialogo transparente con sus grupos de interés, responsabilizándose de las consecuencias e impactos que se derivan de sus acciones" (Ministerio de Trabajo y de Asuntos Sociales, 2007: 7). 
- La RSE en una empresa conlleva una restructuración de sus sistemas de gestión, actualizándolos y convirtiéndolos en más ágiles, flexibles y eficaces. Se configura la RSE como una nueva concepción de empresa, como una nueva forma de gestión, muy en línea con los debates internacionales actuales, que está exigiendo una empresa más transparente, más sostenible y, en definitiva, más responsable (CEPES, 2011).

En todas las definiciones se constata que la RSE supone el cumplimiento estricto de las normas legales vigentes por parte de las empresas, pero añadiendo de forma voluntaria la asunción de los compromisos y comportamientos éticos en su gestión (incorporando las preocupaciones sociales, laborales y medio-ambientales) y responsabilizándoles de las consecuencias y los impactos que se derivan de sus relaciones con sus grupos de interés (De Castro, 2005). Y todo ello con el carácter de valor añadido que se genera para las organizaciones involucradas.

No obstante, queda pendiente el debate sobre la voluntad u obligatoriedad de su aplicación, fundamentado en consideraciones sobre el cumplimiento únicamente de determinados mínimos legales (Arcas y Briones, 2009). Esta cuestión trasladada a la realidad de los países implica que, en la práctica, muchos de los gobiernos han optado por políticas de "no obligatoriedad" de la RSE, limitándose a potenciar el desarrollo de estándares y prácticas de promoción de la misma (Lozano, Albareda e Ysa, 2005; Chumaceiro, Hernández, Yori y Ziritt, 2013; Observatorio de la Responsabilidad Corporativa, 2012, 2014, 2015).

Para concluir este apartado se hace referencia a las posiciones recogidas en la literatura sobre las relaciones entre las actividades de RSE y los resultados y efectos sobre las organizaciones. En primer lugar, Server y Villalonga (2005) señalan la ventaja competitiva de la RSE al crear confianza y mejorar la reputación de las organizaciones que la practican, generando efectos positivos en el incremento del resultado económico. Posteriormente, Server y Capo (2009) referencian los resultados del estudio de Forética (2008) que indican que el $85 \%$ de los empresarios están de acuerdo en la existencia de efectos beneficiosos de la RSE tanto para la sociedad como para la empresa. Este estudio también muestra ciertas ventajas que las empresas aprecian en la adopción de la RSE: mejora la productividad (51,7\% de las empresas), mayor competitividad (60,4\%), mejora de la gestión (64,2\%), mayor fidelidad de los clientes (73,9\%), mayor aceptación o credibilidad ante la sociedad $(82,4 \%)$ y mejor reputación (86,5\%). No obstante, Arcas y Briones (2009) destacan el bajo interés que la RSE presenta para las empresas españolas, el 4,4\% cree en la RSE y la aplica, el $12,7 \%$ no cree totalmente en ella, pero hace algo relacionado con la misma, el 33,1\% cree en ella, pero no la aplica, el $27 \%$ no cree en su utilidad y no la aplica, y el 4,9\% es escéptico ante la misma, pero cree en su utilidad. Las grandes empresas muestran un grado de sensibilización mayor que las pequeñas, generando un comportamiento más proactivo respecto a la RSE. Estos datos son comparados en el estudio de Forética (2011), donde las empresas españolas opinan mayoritariamente que la RSE genera beneficios mutuos a la sociedad y a las empresas, reconociendo no obstante la dificultad de cuantificarlos. En este periodo de crisis (2008-2010) es posible observar (cuadro 1) una variación importante en la percepción de la RSE entre las pequeñas y grandes empresas. 


\section{Cuadro 1. Variaciones en la percepción empresarial de la RSE (2008-2010)}

\begin{tabular}{|l|cc|}
\hline & $\begin{array}{c}\text { Pequeñas } \\
\text { empresas }\end{array}$ & $\begin{array}{c}\text { Medianas y } \\
\text { grandes empresas }\end{array}$ \\
\hline Beneficios a la empresa y a la sociedad & $\boldsymbol{\nabla} 5,79 \%$ & $\boldsymbol{\Delta} 1,96 \%$ \\
Prácticamente una obligación sin beneficios claros & $\boldsymbol{\nabla} 9,43 \%$ & $\boldsymbol{\nabla} 3,35 \%$ \\
Cuestión de imagen & $\boldsymbol{\Delta} 17,67 \%$ & $\boldsymbol{\nabla} 9,66 \%$ \\
Se deben dirigir recursos a fines más prácticos & $\boldsymbol{\Delta} 7,15 \%$ & $\boldsymbol{\nabla} 14,46 \%$ \\
No hay utilidad pero hay que hacerlo & $\boldsymbol{\nabla} 4,03 \%$ & $\boldsymbol{\nabla} 10,71 \%$ \\
Moda que pasará & $\boldsymbol{\Delta} 7,42 \%$ & $\boldsymbol{\nabla} 10,96 \%$ \\
\hline
\end{tabular}

FUENTE: Informe Forética (2010).

2.2. La Responsabilidad Social Empresarial en la Economía Social: Las cooperativas

Las entidades de Economía Social en España constituyen otra forma de emprender, generar empleo y crear riqueza colectiva diferente a la tradicional, pues ofrecen respuesta al territorio y al entorno donde se ubican, aportando soluciones positivas a las diversas problemáticas planteadas (Pedreño, 2009). Según los datos del informe económico 2009-10 de CEPES, a fecha de 31 de diciembre de 2010, representaban los intereses de 44.693 entidades, ofertando empleo a 2.377.912 personas de diversos sectores y colectivos, generando una facturación de 86.663,48 millones de euros equivalente al 10 por ciento del PIB nacional, y reuniendo a 12.218.185 asociados. Pero su contribución va más allá de la meramente cuantitativa, dado que generan valor añadido social, tratan de resolver desequilibrios económicos, persiguen fines de interés social, y combinan así, la eficiencia empresarial y la responsabilidad social de las organizaciones. Esta posición las convierte en agentes estratégicos de la economía por atender a diversas demandas, posibilitar el desarrollo y contribuir a la estabilidad y pluralismo de los mercados. En la configuración de la Economía Social española, la aprobación de la Ley 5/2011, 29 de marzo de Economía Social ha supuesto un punto de inflexión para el reconocimiento, visibilidad y desarrollo del sector, tanto en el entorno nacional como en el de la Unión Europea. En su definición se integra al conjunto de actividades que desde el ámbito privado llevan a cabo una serie de entidades que persiguen el interés general, económico o social o bien ambos conforme a los principios que orientan la Economía Social en España (CEPES, 2012; Fajardo, 2018). Esta presenta una elevada coherencia y eficacia en el desarrollo real del concepto de RSE y en la configuración de sus relaciones con los grupos de interés. De hecho, la importancia social y económica de las empresas de Economía Social ha sido puesta de manifiesto en abundantes trabajos e informes a lo largo del tiempo (Faura y Monzón, 1999; Gui, 1991; Barea, 1990, 1991; Barrera, 2007; Pérez, Esteban y Gargallo, 2009; Chaves y Monzón, 2018; Spear, Defourny, Favreau y Laville, 2001). 
En esta labor, también se han ido incorporando sugerencias metodológicas para poner de relieve el papel de la Economía Social como realidad social, señalando que está inmersa en un sistema socioeconómico global y no constituye otra economía, y que por otro lado "...la función de las entidades de la economía social se halla íntimamente ligada a la satisfacción de necesidades sociales, a la mejora de la calidad de vida de la población y a la resolución de problemas sociales latentes" (Chaves, 1999: 22).

En este esquema, se reconocen diversas actuaciones donde las empresas de Economía Social realizan actuaciones de RSE (De Castro, 2005) como son la generación de empleo, el fomento y la creación de capital social, la regulación y equilibrio de sectores económicos y sociales, la generación de riqueza en sectores donde no llega el inversor tradicional, el desarrollo del espíritu emprendedor, la participación en la gestión económica, la aportación de prestaciones sociales complementarias, la inclusión e inserción social y laboral de colectivos de difícil empleabilidad, la integración de personas con discapacidad en la actividad económica, la mejora en el acceso a la vivienda, los servicios educativos locales, la creación de infraestructuras y dotaciones sociales, la aglutinación del trabajo autónomo, la asistencia sanitaria personalizada, el desarrollo de grupos empresariales específicos que proponen una creación y distribución más equitativa de la riqueza, así como la medición y objetivación del concepto de RSE.

A partir de la distinción de los diversos agentes integrantes de la Economía Social y sus relaciones, Chaves (1997) y Sajardo (1998) proponen un esquema de tres niveles para la Economía Social, en el cual destacan la figura de las cooperativas. Partiendo del enfoque de tercer nivel, Barea y Monzón (2002) argumentan que las cooperativas constituyen el núcleo duro y eje vertebrador de la Economía Social, fundamentado en la doble condición de sus agentes interesados, como socios y usuarios, productores para el mercado y posibles destinatarios de la distribución de los excedentes (GarcíaGutiérrez, 1992). Estas organizaciones constituyen el marco teórico-práctico del estudio realizado a través de las publicaciones de memorias y actuaciones de RSE llevadas a cabo por las mismas.

Diversos estudios (Caballer et al., 1987; Server y Segura, 1990; Moyano y Fidalgo, 2001; Vidal, Segura y Rayos, 2001; Gómez-Limón et al., 2003; Ruiz, Hernández y García, 2006; Bel y Ausin, 2007; Montegut y Cristóbal, 2012; Juliá y Meliá, 2008) han mostrado la eficacia del cooperativismo, primeramente como modelo empresarial equilibrado con los objetivos de competencia y competitividad, y en segundo lugar como herramienta de compromiso social mediante la generación y mantenimiento del empleo y la aportación de valores sociales en el ámbito laboral (CEPES, 2015; Coque, 2008), medioambiental (Cooperativas Agroalimentarias, 2010) y económico (Sajardo-Moreno y Chaves-Sajardo, 2017, 2017). En este sentido, según argumentan López y Marcuello (2006), el papel de las cooperativas no se limita a su actuación como competidoras en el mercado, sino que va más allá, actuando como entidades que desarrollan instrumentos donde se combinan aspectos económicos y sociales propios de la RSE. La propia configuración y organización empresarial de las cooperativas permite integrar como socios a diferentes grupos de interés fomentando el dialogo, la participación democrática en la toma de decisiones, la transparencia y la confianza (Vargas y Vaca, 2005; Carrasco, 2005). A la vez, según el análisis de los valores ${ }^{5}$ del movimiento cooperativo ${ }^{6}(\mathrm{ACl}, 2008)$ se encuentran en consonancia 
con la ética, honestidad, respeto a los derechos humanos y transparencia, referencias básicas de la RSE. Otros autores (Palomo y Valor, 2004; Bel y Marín, 2008; Arcas y Briones, 2009) sostienen que las cooperativas pueden ejercer la RSE de forma más eficaz que las empresas capitalistas, debido a su propia naturaleza, cultura, valores y principios que rigen su funcionamiento (Ceballo, 2005). Estas consideraciones pueden ser constatadas en el análisis comparativo entre los principios cooperativos (ACl, 1995) y los principios y valores considerados para la RSE, resumidos en el cuadro 2.

\section{Cuadro 2. Concordancia de valores y principios del cooperativismo y la RSE}

\begin{tabular}{|c|c|}
\hline Valores del Cooperativismo (ACl) & Definición de RSE (Foro de Expertos MTAS) \\
\hline \multicolumn{2}{|c|}{ Valores } \\
\hline \multicolumn{2}{|l|}{ Basados en valores como: } \\
\hline - AYUDA MUTUA & - ÉTICA \\
\hline - RESPONSABILIDAD & - HONESTIDAD \\
\hline - DEMOCRACIA & - RESPETO A LOS DERECHOS HUMANOS \\
\hline - IGUALDAD & - TRANSPARENCIA \\
\hline - EQUIDAD Y SOLIDARIDAD & \\
\hline \multicolumn{2}{|c|}{ Otros valores ÉTICOS según la tradición de sus fundadores: } \\
\hline \multicolumn{2}{|l|}{ - HONESTIDAD } \\
\hline \multicolumn{2}{|l|}{ - TRASPARENCIA } \\
\hline \multicolumn{2}{|l|}{ - RESPONSABILIDAD SOCIAL } \\
\hline \multicolumn{2}{|l|}{ - PREOCUPACIÓN POR LOS DEMÁS } \\
\hline \multicolumn{2}{|c|}{ Principios } \\
\hline 1. ADHESIÓN ABIERTA Y VOLUNTARIA & - INTEGRACIÓN \\
\hline $2^{\circ}$. CONTROL DEMOCRÁTICO DE LOS SOCIOS & - PARTICIPACIÓN \\
\hline $3^{\circ}$. PARTICIPACIÓN ECONÓMICA & - TRANSPARENCIA Y EXTENSIÓN \\
\hline $4^{\circ}$. AUTONOMÍA E INDEPENDENCIA & - INTEGRACIÓN \\
\hline 5․ EDUCACIÓN, FORMACIÓN E INFORMACIÓN & - SOSTENIBILIDAD \\
\hline $6^{\circ}$. COOPERACIÓN ENTRE COOPERATIVAS & \\
\hline $7^{\circ}$. COMPROMISO CON LA COMUNIDAD & \\
\hline
\end{tabular}

FUENTE: Elaboración propia.

5.- Las cooperativas se basan en los valores de ayuda mutua, responsabilidad, democracia, igualdad, equidad y solidaridad. Siguiendo la tradición de sus fundadores, sus miembros creen en los valores éticos de honestidad, transparencia, responsabilidad social y preocupación por los demás.

6.- La cooperativa es una forma de organización empresarial basada en la estructura y funcionamiento democráticos. Su actividad se desarrolla atendiendo a los principios cooperativos, aceptados y regulados en los ámbitos autonómico, estatal e internacional: la adhesión voluntaria y abierta de los socios, la gestión democrática, la participación económica de los socios, la educación, formación e información y el interés por la comunidad. 
La literatura académica, referente sobre todo al ámbito cooperativo, evidencia cómo el comportamiento de las empresas de Economía Social basado en su propia naturaleza y sus principios de actuación, constituye la esencia primordial de una empresa socialmente responsable, pues aglutina una cultura de integración y participación consensuada, incorporando pautas de sostenibilidad y adecuación de las dimensiones sociales, económicas y medioambientales (Sajardo-Moreno y ChavésSajardo, 2017; Mozas y Poyatos, 2010; Liger, Stefan, y Britton, 2016).

Partiendo del vínculo entre la RSE y los principios cooperativos, Gallardo y Castilla (2015) identifican estos últimos como guías de actuación para estas entidades, pues abarcan un número importante de aspectos representativos calificables de RSE, como la no discriminación, la cooperación con la comunidad (Mozas y Bernal, 2006), la preocupación ambiental o la responsabilidad ante los trabajadores. Por ello proponen un marco de trabajo para la RSE como herramienta de gestión estratégica que la cooperativa puede utilizar o no, más allá de su forma jurídica, o del convencimiento sobre la relación coste beneficio que conlleva.

En este sentido, las cooperativas pueden ser reconocidas como pioneras en el desarrollo y mantenimiento de la RSE como instrumento de gestión global (Escuela de Economía Social, 2012), siendo necesario proporcionar diversas herramientas que permitan valorar en estas entidades su implicación en conductas de RSE y aproximar los resultados esperados de actuaciones socialmente responsables (Mugarra, 2001; RSECOOP, 2011). En esta línea, el estado de la cuestión confluye en la idoneidad que presenta el cooperativismo como fórmula empresarial para desarrollar aspectos de responsabilidad social (Nachar, 2013), aunque es necesario comprobar que esta filosofía tiene un reflejo efectivo en la actuación de estas entidades, que deben demostrarlo en escenarios y momentos distintos. Así pues, todas las características y requisitos basados en los principios cooperativos pueden plantear hasta qué nivel estas organizaciones pueden ser consideras como empresas socialmente responsables solamente por su naturaleza, siendo esencial comprobar su cumplimento efectivo (Iturrioz y Dopacio, 2009; Castilla, Gallardo y Sánchez, 2015).

\section{Metodología de estudio}

\subsection{Población del estudio, selección de la muestra y metodología}

Para el desarrollo práctico del trabajo, se ha tomado como población objeto de estudio a la totalidad de empresas contenidas en el "Ranking de Empresas Relevantes de Economía Social" correspondiente al año 2010, que figuran en la base de datos de la Confederación Empresarial Española de la Economía Social (CEPES), con el objetivo de presentar un marco de actuación de las empresas cooperativas en 
un momento crítico de la crisis económica-financiera española. En dicho registro constan un total de 719 entidades pertenecientes a todos los sectores de Economía Social en España, ordenadas por tipo de empresa, sector de actividad, facturación (millones de $€$ ), número de empleados, y localidad donde radica su domicilio social. Estas cooperativas han sido seleccionadas por CEPES como claro ejemplo de su importancia y diversidad dentro del conjunto empresarial.

La primera cuestión, resuelta a partir de la información inicial, ha sido la elaboración de una base de datos conteniendo solamente entidades cooperativas, para que posteriormente puedan ser depuradas convenientemente para el estudio. Se ha obtenido un total de 447 cooperativas, agrupadas y estructuradas en 20 subsectores de actividad, correspondientes al período 2010.

Posteriormente, se ha completado la información, tanto cualitativa como cuantitativa, relativa a la visualización de cuestiones y aspectos de RSE llevados a cabo por las cooperativas, realizando un análisis de las publicaciones en diversos medios, como revistas digitales, la página web de CEPES, directorios especializados, confederaciones y asociaciones cooperativas, y principalmente las propias páginas web de las organizaciones objeto de estudio. La información obtenida ha sido ordenada y sistematizada empleando 5 categorías de datos, en las que se seleccionan las variables que reflejan la actuación cooperativa en RSE en una escala de mayor a menor intensidad:

- Publicación de memorias corporativas de RSE y de sostenibilidad.

- Publicación de compromisos con grupos de interés. Información sobre las tres dimensiones (económica, social y medioambiental) de RSE. Órganos de gobierno.

- Información empresarial, social, cultural, medioambiental. Información sobre misión, valores, filosofía histórica, cooperativismo y datos de interés.

- Información institucional sobre objetivos, calidad, productos y atención a usuarios.

- Información sobre calidad y atención a usuarios (información técnica del producto).

También se ha utilizado como criterio complementario de ordenación, la inclusión en algún catalogo publicado de buenas prácticas de RSE en materias de medio ambiente, acción social, creatividad en gestión de empresas, gestión de recursos humanos, innovación, y relación con terceros y comunicación.

El resultado del cruce de las cooperativas con los criterios de información empleados ha permitido configurar una base de datos con una muestra de 36 entidades que contenían alguna de las variables de RSE necesarias para el estudio. A partir de esta muestra inicial, se ha aplicado un muestreo no probabilístico por conveniencia para la elección de los casos a estudiar. La identificación de las cooperativas se ha llevado a cabo con un criterio multi-territorio con el objeto de facilitar la identificación de diversas realidades respecto al desarrollo de la RSE en cooperativas de España. El perfil de las cooperativas seleccionadas señala una muestra multisector y multidimensional, con un elemento común que se concreta en la implantación de actuaciones de RSE en sus organizaciones. Han sido seleccionadas aquellas cooperativas que cumplieron los siguientes requisitos: 
- Haber incorporado prácticas o políticas de RSE.

- Cumplir preferentemente con una antigüedad mínima en la introducción de las mismas de 4 años.

- Ser representativas en su sector (dimensión, facturación, empleados...).

Esta muestra, seleccionada para este trabajo de acuerdo con el objetivo y la metodología de casos, concretada en el cuadro 3 , ha sido depurada nuevamente en función de la información sectorial obtenida de las empresas con forma jurídica de cooperativa tomada a fecha de 15 de abril de 2012 del Sistema de análisis de balances ibéricos de INFORMA (SABI). Esta información resulta necesaria, dado que, como último objetivo del trabajo, se revisan las posibles relaciones entre los comportamientos de RSE observados en estas entidades y los resultados económicos financieros alcanzados por las mismas.

\section{Cuadro 3. Esquema del proceso metodológico para selección de los casos}

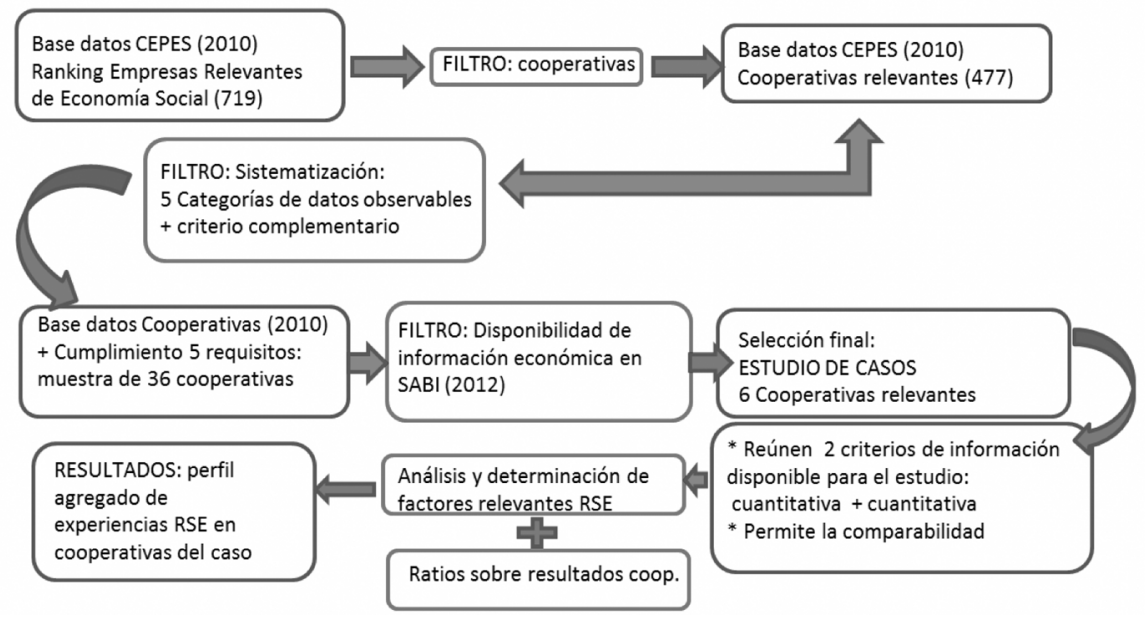

FUENTE: Elaboración propia.

De esta forma se presenta, en primer lugar, el estudio de 6 casos, seleccionados en función de la relevancia de la cooperativa (facturación, número de empleados y sector de actividad). Para cada uno de ellos se procede a realizar una presentación de la entidad y análisis de los resultados en función de la documentación disponible, combinando la utilidad que presentan los datos cualitativos y cuantitativos (Cebreiro y Fernández, 2004; Stake, 2005). En segundo lugar, se aplica un análisis que sintetice las posibles relaciones entre las variables que versan sobre los factores de RSE observados en estas cooperativas y sus resultados económicos (López, Navarro, López y Caba, 2005). 
La metodología de estudio de caso tiene entre sus fines la comprensión de dinámicas singulares (Eisenhardt, 1989), motivo por el cual ha demostrado ser un método de investigación científica adecuada, entre otros, en el ámbito de la dirección y economía de la empresa (Villarreal y Landeta, 2010) y en particular en el análisis de la RSE (Vázquez, 2015), lo que justifica su utilización en la investigación propuesta (Seguí, Seguí, Sarasa y Baviera, 2012).

\subsection{Configuración de los datos para el estudio}

El resultado final de la ordenación y selección de los datos de la muestra inicialmente considerada para el estudio se muestra en el Cuadro 4 (página siguiente). En el mismo destacan algunos de los problemas surgidos para realizar el análisis. Principalmente son dos, el primero relacionado con la falta de homogeneidad en la documentación seleccionada sobre la información de actuaciones de RSE llevadas a cabo por las cooperativas, unido a la imposibilidad de aplicar métodos combinados que permitan una triangulación de datos. Y, en segundo lugar, la existencia de datos perdidos o no incluidos en alguno de los cinco años (periodo 2006-2010) en la base de Sistema Anual de Balances lbéricos sobre la información económica-financiera que inicialmente estaba prevista para el análisis de los resultados económicos de estas cooperativas y su relación con actividades de RSE.

Para la primera de las situaciones, se ha optado por incluir en el estudio de casos aquellas cooperativas que además de su relevancia, presentasen formatos documentales muy parecidos 0 similares, utilizando un sistema numérico-gráfico de visualización de resultados, que puede ser aplicado a todos los casos, expuesto en el apartado siguiente.

En lo referente a la información económica, se ha centrado el análisis en el periodo 2009-2010, pudiendo incluir de esta forma los seis casos seleccionados en el contraste de las prácticas de RSE y resultados cooperativos. 


\section{Cuadro 4. Síntesis de la muestra de cooperativas para el estudio de casos}

\begin{tabular}{|c|c|c|c|c|c|c|c|c|c|}
\hline \multirow{2}{*}{\multicolumn{5}{|c|}{ Cooperativas seleccionadas: caracterización }} & \multicolumn{3}{|c|}{ Posiciones relativas } & \multicolumn{2}{|c|}{ Fuentes de datos } \\
\hline & & & & & \multicolumn{2}{|c|}{ Facturación } & \multirow{2}{*}{$\begin{array}{l}\text { Empleo } \\
\text { Ranking } \\
\text { general } \\
\text { empleo }\end{array}$} & \multirow[b]{2}{*}{$\begin{array}{l}\text { Económicos } \\
\text { Datos Eco- } \\
\text { Financieros } \\
\text { SABI periodo } \\
2010\end{array}$} & \multirow{2}{*}{$\begin{array}{l}\begin{array}{l}\text { Publicación } \\
\text { sobre RSE }\end{array} \\
\text { Actuaciones } \\
\text { RSE periodo } \\
2009-2010\end{array}$} \\
\hline Cooperativa & $\begin{array}{l}\text { Facturación } \\
\text { (Mill €) }\end{array}$ & $\begin{array}{c}\mathrm{N}^{0} \\
\text { empleados }\end{array}$ & Localidad & Sector & $\begin{array}{l}\text { Ranking } \\
\text { general }\end{array}$ & $\begin{array}{l}\text { Ranking } \\
\text { de su } \\
\text { sector }\end{array}$ & & & \\
\hline $\begin{array}{l}\text { Grupo Eroski } \\
\text { Coop. }\end{array}$ & $8.170,0$ & 45.000 & Vizcaya & \begin{tabular}{|c|} 
Distribución / \\
Comercializadoras
\end{tabular} & $1^{0}$ & $1^{\circ}$ & $1^{0}$ & $\begin{array}{l}\text { - Rentabilidad } \\
\text { - Liquidez } \\
\text { - Margen } \\
\text { - Gastos } \\
\text { - Resultados }\end{array}$ & $\begin{array}{l}\text { Memoria } \\
\text { y Anuario } \\
\text { de RSE }\end{array}$ \\
\hline $\begin{array}{l}\text { Consum } \\
\text { Coop. }\end{array}$ & $1.675,5$ & 9.889 & Valencia & $\begin{array}{l}\text { Agroalimentaria } \\
\text { (agricultura) y } \\
\text { distribución } \\
\text { comercial }\end{array}$ & $2^{0}$ & $2^{0}$ & $2^{0}$ & $\begin{array}{l}\text { - Rentabilidad } \\
\text { - Liquidez } \\
\text { - Margen } \\
\text { - Gastos } \\
\text { - Resultados }\end{array}$ & $\begin{array}{l}\text { Memoria de } \\
\text { sostenibilidad }\end{array}$ \\
\hline $\begin{array}{l}\text { Anecoop } \\
\text { S.Coop. }\end{array}$ & 450,8 & 199 & Valencia & $\begin{array}{l}\text { Agroalimentaria } \\
\text { (agricultura) y } \\
\text { distribución } \\
\text { comercial }\end{array}$ & $12^{\circ}$ & $5^{0}$ & $105^{\circ}$ & $\begin{array}{l}\text { - Rentabilidad } \\
\text { - Liquidez } \\
\text { - Margen } \\
\text { - Gastos } \\
\text { - Resultados }\end{array}$ & $\begin{array}{l}\text { Memoria RS } \\
\text { corporativa. } \\
\text { Compromisos } \\
\text { con clientes, } \\
\text { socios y sociedad. } \\
\text { Dimensión } \\
\text { Economía y } \\
\text { Social (RSE) }\end{array}$ \\
\hline $\begin{array}{l}\text { S. Ganadera } \\
\text { Valle de los } \\
\text { Pedroches } \\
\text { (COVAP) }\end{array}$ & 227,27 & 699,0 & Córdoba & $\begin{array}{c}\text { Agroalimentaria } \\
\text { (agricultura) } \\
\text { Ganadería }\end{array}$ & $18^{\circ}$ & $6^{\circ}$ & $31^{\circ}$ & $\begin{array}{l}\text { - Rentabilidad } \\
\text { - Liquidez } \\
\text { - Margen } \\
\text { - Gastos } \\
\text { - Resultados }\end{array}$ & $\begin{array}{l}\text { Catálogo de } \\
\text { buenas prácticas } \\
\text { en RSE. } \\
\text { Información } \\
\text { empresa, } \\
\text { medioambiental, } \\
\text { objetivos, } \mathrm{H}^{\mathrm{a}} \text { Coop. } \\
\text { y filosofía (valores). }\end{array}$ \\
\hline $\begin{array}{l}\text { Arento, Grupo } \\
\text { Coop. Agro- } \\
\text { alimentario } \\
\text { de Aragón, } \\
\text { S. Coop. }\end{array}$ & 121,7 & 26,0 & Zaragoza & $\begin{array}{l}\text { Agroalimentaria } \\
\text { (distribución } \\
\text { comercial) }\end{array}$ & $39^{\circ}$ & $13^{\circ}$ & $83^{\circ}$ & $\begin{array}{l}\text { - Rentabilidad } \\
\text { - Liquidez } \\
\text { - Margen } \\
\text { - Gastos } \\
\text { - Resultados }\end{array}$ & $\begin{array}{l}\text { Catálogo de } \\
\text { buenas prácticas } \\
\text { en RSE. } \\
\text { Información } \\
\text { medioambiental } \\
\text { y calidad. }\end{array}$ \\
\hline $\begin{array}{l}\text { Alimer, } \\
\text { S.Coop. }\end{array}$ & 118,67 & 1.478 & Murcia & $\begin{array}{l}\text { Agroalimentaria } \\
\text { (distribución } \\
\text { comercial) }\end{array}$ & $43^{\circ}$ & $16^{\circ}$ & $14^{\circ}$ & $\begin{array}{l}\text { - Rentabilidad } \\
\text { - Liquidez } \\
\text { - Margen } \\
\text { - Gastos } \\
\text { - Resultados }\end{array}$ & $\begin{array}{l}\text { Memoria RS } \\
\text { Corporativa. } \\
\text { Catálogo de } \\
\text { Buenas Prácticas } \\
\text { en RSE } \\
\text { (Innovación). }\end{array}$ \\
\hline $\begin{array}{l}\text { Valores medios } \\
\text { cooperativas }\end{array}$ & 68,0 & 337,72 & & & & & tal c & 7 cooperativas & \\
\hline
\end{tabular}

FUENTE: Elaboración propia a partir de datos de CEPES (2012) y SABI (2010). 


\subsection{Metodología del caso y determinación de factores relevantes de} Responsabilidad Social Empresarial (RSE)

Partiendo de las proposiciones correspondientes al marco de las teorías de las demandas de grupos de interés y de la noción plural de RSE utilizada por el GRI para evaluar los datos y evidencias de la actuación de las cooperativas desde la triple óptica económica, social y medioambiental (TBL), se aplica la metodología del caso sobre la muestra (Yin, 1989; 1994; Eisenhardt, 1989; Ryan, Scapens y Theobald, 2004; Castro, 2010; Seguí-Mas, Seguí-Mas, Sarasa y Baviera, 2012). Se trata de identificar el patrón de comportamiento específico en los casos de cooperativas seleccionadas, buscando resultados y evidencias con una finalidad "explicativa" en un periodo intermedio de la crisis económica en España.

En este proceso, primeramente, se ha procedido a determinar los factores relevantes de RSE relativos a las tres dimensiones de la Responsabilidad Social de la Empresa, según el modelo RSE COOP para la gestión de la RSE en este tipo de organizaciones (RSECOOP, 2007; 2011) ${ }^{7}$, para su análisis y observación en estas cooperativas, y que constituyen el patrón especifico que se aplicará a los casos estudiados. La recopilación de datos se realiza mediante el análisis de la información publicada, anteriormente referenciada, por estas entidades en distintos medios, relativa al periodo 2009-2010.

\subsubsection{Determinación de factores relevantes de RSE}

Partiendo de la definición y conceptualización de la RSE, y teniendo en cuenta las cuatro hipótesis siguientes:

a) La RSE supone una verdadera estrategia empresarial que es complementaria con el modelo de gestión de los negocios en las entidades cooperativas y que refleja sus verdaderos valores y la filosofía de su actuación.

b) La extensión de la RSE como elemento substancial para la competitividad de las empresas hace más atractivas a las cooperativas socialmente responsables en relación a los socios, trabajadores, clientes, proveedores y la sociedad.

c) El éxito de la RSE se fundamenta en el dialogo con un amplio abanico de grupos de interés (trabajadores, proveedores, comunidad, etc.) con el objetivo de configurar una relación de colaboración que culmine con la creación de valor, que refuerza la consecución de las expectativas, anticipación de riesgos y reducción de costes.

d) La RSE también atribuye por parte de las cooperativas una respuesta comercial al concepto de desarrollo sostenible, pues engloba las responsabilidades de carácter económico, social y medioambiental. 
Se han definido las cinco áreas correspondientes a las acciones donde las cooperativas realizan y enmarcan la RSE y que comprenden lo relativo a las cuestiones éticas, las personas, la comunidad, la competencia y el medio ambiente. En las mismas, se integran los factores que configuran la RSE en lo relativo a los tres ámbitos considerados, con la finalidad de comprobar si la RSE ofrece beneficios a las cooperativas seleccionadas, tratando de responder a cuestionamientos como:

1. ¿Cuál es el grado de desarrollo que presentan las prácticas de RSE en estas cooperativas?

2. ¿Cuál es el grado de integración y/o compromiso global de la cooperativa en actuaciones de RSE? 8

3. ¿Puede existir y revelarse algún tipo de relación entre los comportamientos de RSE observados en las cooperativas objeto de estudio y los resultados de su actuación empresarial?

Para ello se ha partido de los cuestionarios/criterios definidos y empleados en el trabajo "Estudio de la Responsabilidad Social en al empresas de Economía Social de Andalucía 2012" (Escuela de Economía Social, 2012) sobre el desempeño y conocimiento de la RSE. Posteriormente, se han anexado las áreas de RSE definidas en el Manual del Autoevaluación de Responsabilidad Social Empresarial (DERES), e integrado por último, la delimitación y conceptualización de los tres vectores sobre los que se estructura la actuación en términos de Responsabilidad Social Corporativa empleados en el modelo de RSE Coop (COCETA, 2010, 2011).

De esta forma, para realizar una evaluación básica se propone una herramienta estandarizada que contiene un cuestionario preparado en el que se ofrece una descripción de los aspectos englobados en cada una de las áreas de RSE consideradas. Los grados de cumplimiento son reflejados mediante una escala tipo Likert de 4 puntos, correspondiendo las opciones con las siguientes observaciones:

- $0(\mathrm{~N} / \mathrm{C})=$ no corresponde, no es aplicable para este caso. No informa.

- no contempla o realiza dicha acción o política.

- es realizada a veces.

- si es realizada (siempre).

En alguno de los ítems considerados se han podido extraer informaciones que generan un porcentaje, una cifra u otro tipo de información. En estos casos, estos datos, aunque de uso interno, se han incorporado en el análisis para facilitar la visualización sobre si la política o actuación de RSE está siendo aplicada de forma efectiva.

Así pues, el proceso final de recopilación de los criterios empleados se concreta en el Anexo I, denominado "factores relevantes de Responsabilidad Social Empresarial". La idoneidad del mismo está basada en la utilización de indicadores que han sido construidos y contrastados por diversas entidades con solvencia reconocida, lo cual garantiza su perfecta adecuación al concepto de RSE, tanto en el

8.- Mediante la utilización de indicadores utilizados como diagnóstico de la situación. 
ámbito nacional como en el internacional. Entre los mismos destacan: La Guía G3.1 del Global Reporting Iniciative para elaborar memorias de sostenibilidad, la norma SEG 21 (Forética Gestión Ética) como estándar de gestión de la RS europea que permite auditar procesos y alcanzar certificaciones en Gestión Ética y RSE, los 10 principios del Pacto Global de Naciones Unidas y diversas normas que reflejan estándares en el control de calidad pertenecientes a la familia ISO $(9000,9001,14000)$, y la herramienta RSE.COOP ${ }^{9}$, especialmente diseñada para entidades cooperativas y de Economía Social que permite realizar diagnósticos en materia de RSE y fijar planes de acción de mejora en esta materia.

En el mismo se han recogido un total de 74 preguntas relativas a cuatro criterios (compromisos) relacionados con el ámbito económico de la RSE, cuatro criterios sobre cuestiones medioambientales, y doce criterios relacionados con aspectos sociales.

Siguiendo el protocolo establecido para el estudio de los casos señalados, una vez recopilada la documentación oportuna, y con el objeto de aplicar de forma homogénea la herramienta que contiene estructurados los distintos factores relevantes de RSE se procede a la visualización de los resultados y al análisis correspondiente. Así, como síntesis, se calcula el promedio alcanzado en cada uno de los criterios considerados, como también para cada uno de los ámbitos de RSE, y se informa sobre el total o global de actuaciones de Responsabilidad Social conseguido en el caso. Estos valores son trasladados a los ejes de un círculo, lo que permite visualizar mediante el área correspondiente, los resultados de forma individual, construyendo un "mapa gráfico de RSE" que refleja el perfil agregado de experiencias en RSE, que permite comparaciones con otros resultados obtenidos en distintos estudios (COCETA, 2010).

La figura resultante permite ilustrar la situación global de la empresa en términos de RSE, de forma que cuanto más se acerca a la figura del círculo, más determina un mayor índice de desarrollo de la RSE en la cooperativa. Este método permite comparar de forma numérica y gráfica los diagnósticos efectuados sobre el cumplimiento de acciones de RSE alcanzados en cada uno de los casos de cooperativas seleccionadas. Además, una vez contrastada su utilidad, podría ser utilizado para el conjunto de cooperativas, así como como para otras entidades de la Economía Social.

\subsubsection{Elección de ratios sobre resultados económico-financieros}

Teniendo en cuenta diversos estudios sobre el sector cooperativo (Caballer, 1982; Segura y Oltra, 1995; Montegut et al., 2002), que justifican la dinámica de inversiones, el esfuerzo modernizador (Martín y Vidal, 2001), la maximización de pagos a los socios (Gómez-Limón et al., 2003), o la adecuación de la dimensión de la cooperativa (Moyano y Fidalgo, 2001), y considerando la muestra heterogénea de cooperativas, se han seleccionado ${ }^{10}$ las ratios que se muestran en la tabla 1.

9.- El desarrollo de esta herramienta, plasmado en un software específico, se basa en la metodología de indicadores del GRI. Además, a estos indicadores se han incluido 30 más, que miden algunas especificidades de funcionamiento de las entidades de Economía Social. Todo este trabajo derivó en la edición de una Guía específica para la Economía Social, avalada por el global Reporting Iniciative, máximo referente en guías de Responsabilidad Social Empresarial.

10.- En función de la operatividad y disponibilidad de datos para su cálculo. 


\section{Tabla 1. Ratios utilizados con posiciones de los agentes interesados}

\begin{tabular}{|c|c|c|c|}
\hline $\begin{array}{l}\text { Perspectiva coop. } \\
\text { y/o grupos de } \\
\text { interés cooperativos }\end{array}$ & Objetivos perseguidos & Ratios de medición & Definición \\
\hline $\begin{array}{c}1^{\circ} \text { Socio como } \\
\text { proveedor }\end{array}$ & Rentabilidad económica & $\begin{array}{l}\text { Rentabilidad Económica } \\
\text { (Return on total assets) (\%) }\end{array}$ & $\begin{array}{l}\text { Resultados antes de impuesto / } \\
\text { Activo total }\end{array}$ \\
\hline $\begin{array}{cc}2^{\circ} & \text { Socio como } \\
\text { propietario }\end{array}$ & Rentabilidad financiera & $\begin{array}{l}\text { Resultado antes de impuestos } \\
\text { sobre F. Propios (Return on } \\
\text { shareholders funds) (\%) }\end{array}$ & $\begin{array}{l}\text { Beneficio antes de impuesto / } \\
\text { Recursos propios }\end{array}$ \\
\hline \multirow{3}{*}{$\begin{array}{l}3^{\circ} \text { Cooperativa } \\
\text { como empresa } \\
\text { que opera } \\
\text { en el mercado }\end{array}$} & \multirow{3}{*}{$\begin{array}{l}\text { Objetivos corporativos de } \\
\text { rendimiento como } \\
\text { unidad empresarial }\end{array}$} & $\begin{array}{l}\text { Liquidez general o Solvencia } \\
\text { a C.P. (Current ratio) }\end{array}$ & Activo circulante / Pasivo circulante \\
\hline & & $\begin{array}{l}\text { Liquidez inmediata } \\
\text { (Liquidity ratio) }\end{array}$ & $\begin{array}{l}\text { (Activo circulante-existencias) / } \\
\text { Pasivo circulante }\end{array}$ \\
\hline & & $\begin{array}{l}\text { Margen comercial } \\
\text { (Profit margin ratio) } \\
\end{array}$ & $\begin{array}{l}\text { Resultados antes impuestos / } \\
\text { Ingresos explotación }\end{array}$ \\
\hline \multirow[t]{2}{*}{$\begin{array}{l}4^{\circ} \text { Los empleados } \\
\text { de la cooperativa }\end{array}$} & \multirow[t]{2}{*}{$\begin{array}{l}\text { Resultados como empresa } \\
\text { y satisfacción de los } \\
\text { trabajadores }\end{array}$} & $\begin{array}{l}\text { Gastos de personal sobre } \mathrm{N}^{\circ} \\
\text { empleados (Average cost } \\
\text { of employer/ Year). Mil. }\end{array}$ & $\begin{array}{l}\text { Coste de personal / } \\
N^{0} \text { empleados año }\end{array}$ \\
\hline & & $\begin{array}{l}\text { Resultados antes de impuestos / } \\
\mathrm{N}^{\circ} \text { empleados (Profit per } \\
\text { employee) Mil. }\end{array}$ & $\begin{array}{l}\text { Beneficio antes impuestos / } \\
N^{\circ} \text { empleados año }\end{array}$ \\
\hline
\end{tabular}

FUENTE: Elaboración propia a partir de López et. al (2006).

\section{Resultados del análisis de casos}

A continuación, se presentan los principales resultados de los casos analizados. Los análisis empíricos del trabajo se han obtenido mediante la utilización del programa informático SPSS 15.0, así como de Microsoft Excel para los primeros tratamientos de datos.

\subsection{Caso 1. Cooperativa Grupo Eroski}

(Memoria Eroski 2010 (58 páginas) y Anuario de RSE). 


\section{Figura 1. Mapa gráfico y perfil de actuaciones RSE en Eroski}

\section{Puntuaciones promedios ámbitos RSE}

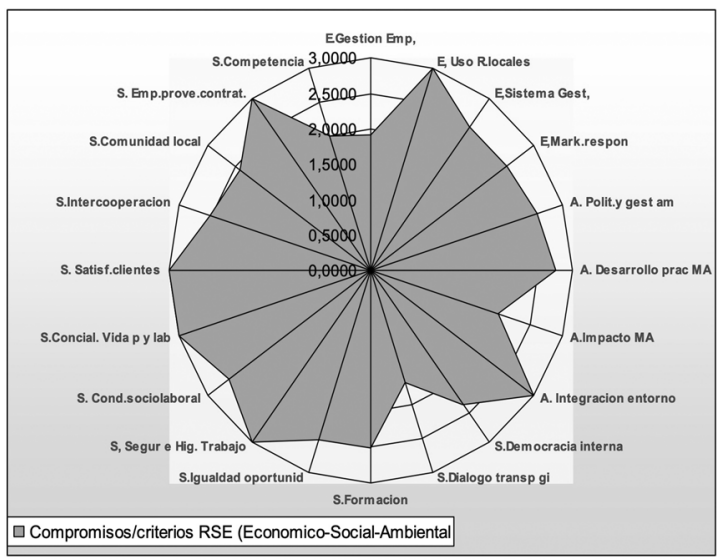

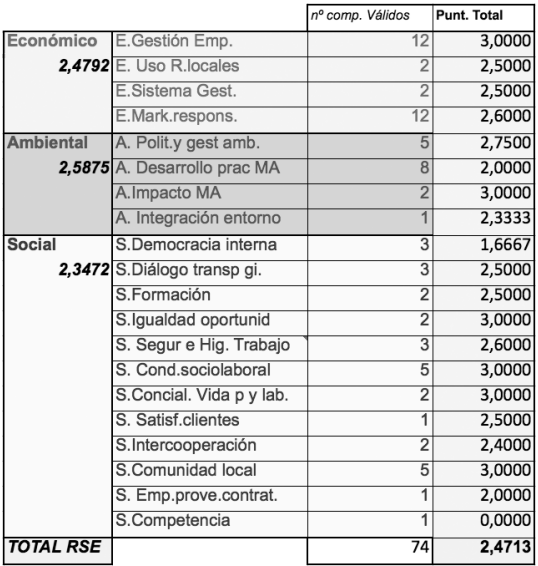

FUENTE: Elaboración propia.

\subsection{Caso 2. Cooperativa Consum S.Coop.}

(Memoria de sostenibilidad, Año 2010, 126 páginas)

\section{Figura 2. Mapa gráfico y perfil de actuaciones RSE en Consum}

\section{Puntuaciones promedios ámbitos RSE}

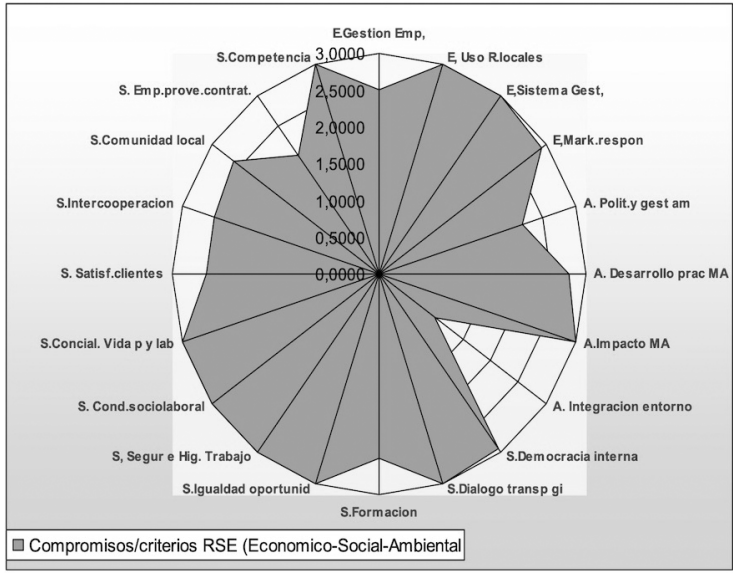

\begin{tabular}{|c|c|c|c|}
\hline & & \\
\hline & $n^{\circ}$ comp. Válidos & Puntu.Total \\
\hline Económico & E.Gestión Emp. & 12 & 2,5000 \\
\hline \multirow[t]{3}{*}{2,8542} & E. Uso R.locales & 2 & 3,0000 \\
\hline & E.Sistema Gest. & 2 & 3,0000 \\
\hline & E.Mark.respons. & 12 & 2,9167 \\
\hline Ambiental & A. Polity gest amb. & 5 & 2,2000 \\
\hline \multirow{3}{*}{2,2375} & A. Desarrollo prac MA & 8 & 2,7500 \\
\hline & A.Impacto MA & 2 & 3,0000 \\
\hline & A. Integración entorno & 1 & 1,0000 \\
\hline Social & S.Democracia interna & 3 & 2,9333 \\
\hline \multirow[t]{11}{*}{2,5083} & S.Diálogo transp gi. & 3 & 3,0000 \\
\hline & S.Formación & 2 & 2,5000 \\
\hline & S.Igualdad oportunid & 2 & 3,0000 \\
\hline & S. Segur e Hig. Trabajo & 3 & 3,0000 \\
\hline & S. Cond.sociolaboral & 5 & 3,0000 \\
\hline & S.Concial. Vida p y lab. & 2 & 3,0000 \\
\hline & S. Satisf.clientes & 1 & 2,5000 \\
\hline & S.Intercooperación & 2 & 2,5000 \\
\hline & S.Comunidad local & 5 & 2,6000 \\
\hline & S. Emp.prove.contrat. & 1 & 2,0000 \\
\hline & S.Competencia & 1 & 3,0000 \\
\hline TOTAL RSE & & 74 & 2,5333 \\
\hline
\end{tabular}

FUENTE: Elaboración propia. 


\subsection{Caso 3. Cooperativa Anecoop S.Coop.}

(Memoria Corporativa, Compromisos con clientes, socios y sociedad, Dimensión Económica y Social (RSE), Periodo 2010-2011, 71 páginas).

\section{Figura 3. Mapa gráfico y perfil de actuaciones RSE en Anecoop}

\section{Puntuaciones promedios ámbitos RSE}

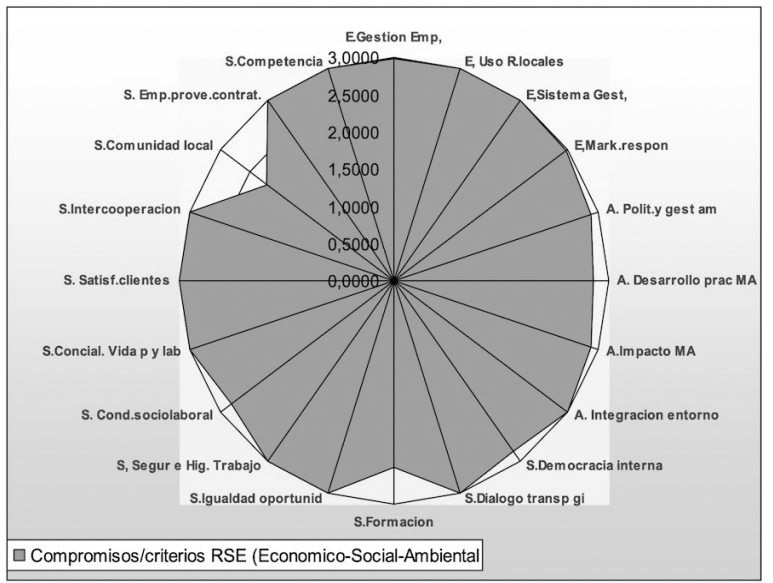

\begin{tabular}{|c|c|c|c|}
\hline & & \multirow[b]{2}{*}{$n^{\circ}$ comp. Válidos } & \multirow[b]{2}{*}{ Puntu.Total } \\
\hline & & & \\
\hline Económico & E.Gestión Emp. & 12 & 2,9833 \\
\hline \multirow[t]{3}{*}{2,9917} & E. Uso R.locales & 2 & 3,0000 \\
\hline & E.Sistema Gest. & 2 & 3,0000 \\
\hline & E.Mark.respons. & 12 & 2,9833 \\
\hline Ambiental & A. Polit.y gest amb. & 5 & 2,9000 \\
\hline \multirow[t]{3}{*}{2,8969} & A. Desarrollo prac MA & 8 & 2,7875 \\
\hline & A. Impacto MA & 2 & 2,9000 \\
\hline & A. Integración entorno & 1 & 3,0000 \\
\hline Social & S. Democracia interna & 3 & 2,8333 \\
\hline \multirow[t]{11}{*}{2,6250} & S. Diálogo transp gi. & 3 & 3,0000 \\
\hline & S.Formación & 2 & 2,5000 \\
\hline & S. Igualdad oportunid & 2 & 3,0000 \\
\hline & S. Segur e Hig. Trabajo & 3 & 3,0000 \\
\hline & S. Cond.sociolaboral & 5 & 2,8000 \\
\hline & S.Concial. Vida p y lab. & 2 & 3,0000 \\
\hline & S. Satisf.clientes & 1 & 3,0000 \\
\hline & S. Intercooperación & 2 & 3,0000 \\
\hline & S.Comunidad local & 4 & 2,2000 \\
\hline & S. Emp.prove.contrat. & 1 & 3,0000 \\
\hline & S.Competencia & 1 & 3,0000 \\
\hline TOTAL RSE & & 73 & 2,8378 \\
\hline
\end{tabular}

FUENTE: Elaboración propia.

\subsection{Caso 4. SCA Ganadera del Valle de los Pedroches (COVAP)}

(Catálogo de buenas prácticas en RSE (Medioambiental) e Información página Web cooperativa. Información empresa, medioambiental, calidad, objetivos, historia cooperativa y filosofía (valores). 


\section{Figura 4. Mapa gráfico y perfil de actuaciones RSE en COVAP}

\section{Puntuaciones promedios ámbitos RSE}

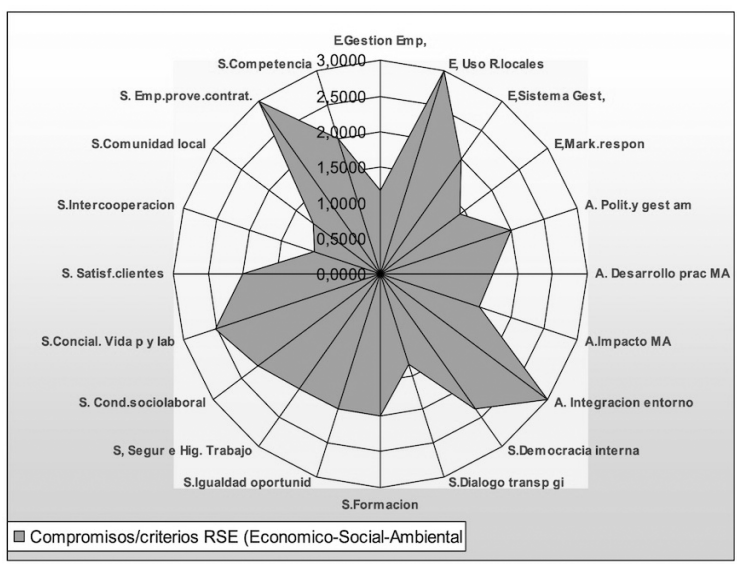

\begin{tabular}{|c|c|c|c|}
\hline & & $n^{\circ}$ comp. Válidos & Puntu.Total \\
\hline Económico & E.Gestión Emp. & 12 & 1,1667 \\
\hline \multirow[t]{3}{*}{1,8958} & E. Uso R.locales & 2 & 3,0000 \\
\hline & E.Sistema Gest. & 2 & 2,0000 \\
\hline & E.Mark.respons. & 12 & 1,4167 \\
\hline \begin{tabular}{|l} 
Ambiental \\
\end{tabular} & A. Polit.y gest amb. & 5 & 2,0000 \\
\hline \multirow[t]{3}{*}{2,0313} & A. Desarrollo prac MA & 8 & 1,6250 \\
\hline & A.Impacto MA & 2 & 1,5000 \\
\hline & A. Integración entorno & 1 & 3,0000 \\
\hline Social & S.Democracia interna & 3 & 2,3333 \\
\hline \multirow[t]{11}{*}{1,7694} & S.Diálogo transp gi. & 3 & 1,3333 \\
\hline & S.Formación & 2 & 2,0000 \\
\hline & S.Igualdad oportunid & 2 & 2,0000 \\
\hline & S. Segur e Hig. Trabajo & 3 & 2,0000 \\
\hline & S. Cond.sociolaboral & 5 & 2,2000 \\
\hline & S.Concial. Vida p y lab. & 2 & 2,5000 \\
\hline & S. Satisf.clientes & 1 & 2,0000 \\
\hline & S.Intercooperación & 2 & 1,0000 \\
\hline & S.Comunidad local & 5 & 1,2000 \\
\hline & S. Emp.prove.contrat. & 1 & 3,0000 \\
\hline & S.Competencia & 1 & 2,0000 \\
\hline TOTALRSE & & 74 & 1,8988 \\
\hline
\end{tabular}

FUENTE: Elaboración propia.

\subsection{Caso 5. Arento Grupo Cooperativo Agroalimentario de Aragón S. Coop.}

Catálogo de buenas prácticas de RSE (Medioambiental) e información página Web cooperativa.

\section{Figura 5. Mapa gráfico y perfil de actuaciones RSE en Arento}

\section{Puntuaciones promedios ámbitos RSE}

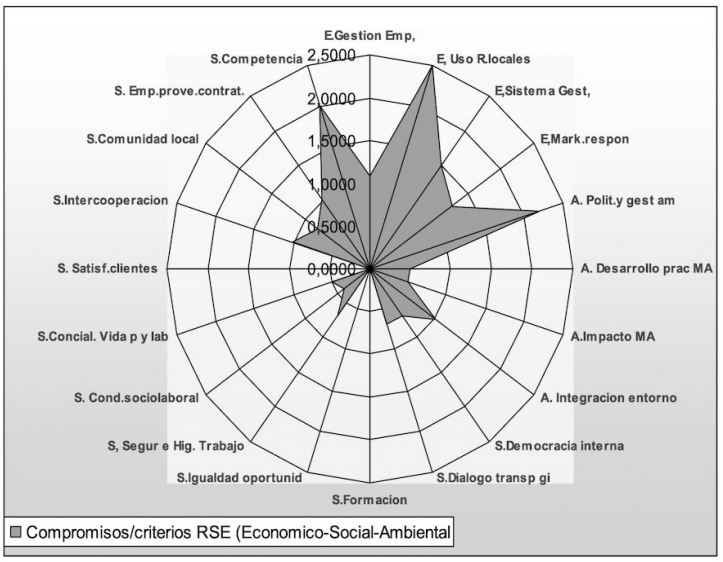

\begin{tabular}{|c|c|c|c|}
\hline & & & \\
\hline Economico & E.Gestión Emp. & 8 & 10833 \\
\hline 1,5833 & E. Uso R.locales & 2 & 2,5000 \\
\hline & E.Sistema Gest. & 1 & 1,5000 \\
\hline & E.Mark.respons. & 9 & 1,2500 \\
\hline Ambiental & A. Polit.y gest amb. & 5 & 2,2000 \\
\hline 1,0500 & A. Desarrollo prac MA & 3 & 0,5000 \\
\hline & A.Impacto MA & 1 & 0,5000 \\
\hline & A. Integración entorno & 1 & 1,0000 \\
\hline Social & S.Democracia interna & 1 & 0,6667 \\
\hline 0,5861 & S.Diálogo transp gi. & 2 & 0,6667 \\
\hline & S.Formación & 0 & 0,0000 \\
\hline & S.Igualdad oportunid & 0 & 0,0000 \\
\hline & S. Segur e Hig. Trabajo & 2 & 0,6667 \\
\hline & S. Cond.sociolaboral & 2 & 0,4000 \\
\hline & S.Concial. Vida py lab. & 1 & 0,5000 \\
\hline & S. Satisf.clientes & 0 & 0,0000 \\
\hline & S.Intercooperación & 1 & 1,0000 \\
\hline & S.Comunidad local & 3 & 0,8000 \\
\hline & S. Emp.prove.contrat. & 1 & 1,0000 \\
\hline 0 & S.Competencia & 1 & 2,0000 \\
\hline TOTALRSE & & 44 & 1,0731 \\
\hline
\end{tabular}

FUENTE: Elaboración propia.

CIRIEC-España, Revista de Economía Pública, Social y Cooperativa 
(Memoria RS corporativa 2008, Año 2008, 38 páginas. Catálogo de buenas prácticas de RSE (Innovación) e Información página Web cooperativa).

\section{Figura 6. Mapa gráfico y perfil de actuaciones RSE en Alimer}

\section{Puntuaciones promedios ámbitos RSE}

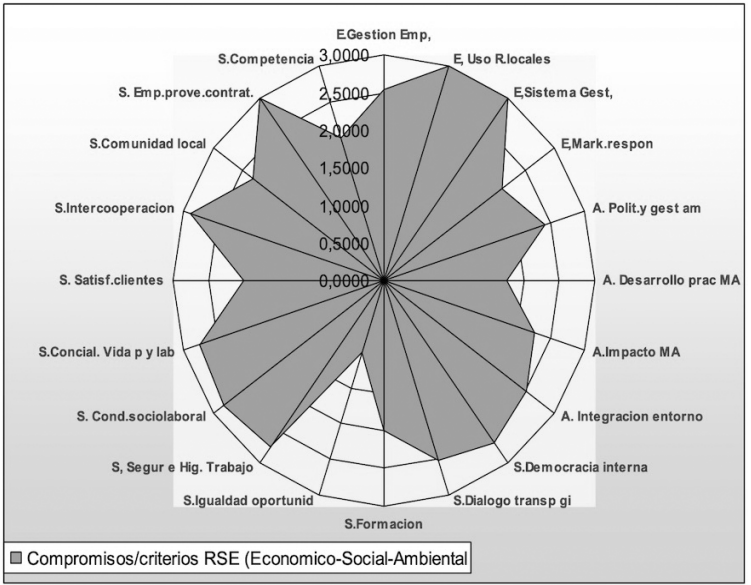

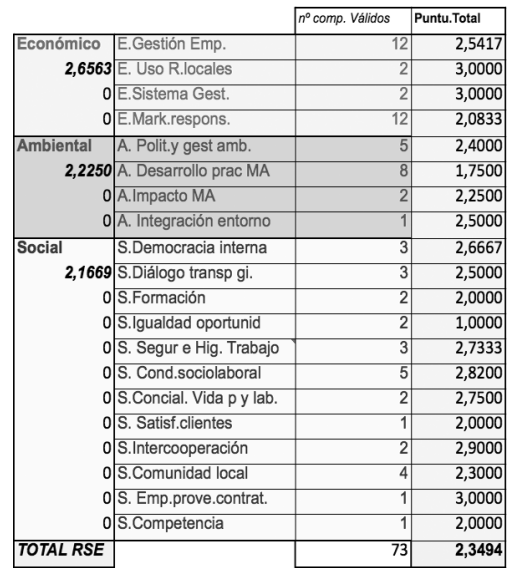

FUENTE: Elaboración propia.

Una vez mostrados los índices de desarrollo de la RSE, a partir de la información tomada de SABI, se han obtenido los valores medios correspondientes a las ratios seleccionadas para medir la rentabilidad y el resultado económico-financiero de estas cooperativas en el año 2010 (tabla 2), y se ha elaborado la matriz de correlaciones para los casos descritos con el objeto de observar las posibles relaciones ${ }^{11}$ entre las variables de RSE y rentabilidad (tabla 3).

11.- La metodología del caso empleada determina una muestra de 6 empresas, que impide la aplicación de los contrastes estadísticos al no superar $N>=30$. Tampoco se pueden establecer y/o modelizar relaciones de causalidad para el conjunto de cooperativas españolas en 2010 mediante la correspondiente regresión, en el sentido de que la RSE influya en los resultados económicos o viceversa. 


\section{Tabla 2. Estadístico resultados en variables RSE y rentabilidad de cooperativas del estudio}

\begin{tabular}{|c|c|c|c|c|c|}
\hline \multicolumn{2}{|c|}{ Variables } & Media & Stand. Desv. & Min. & Max. \\
\hline \multirow{4}{*}{ 岩 } & Puntuación Global RSE & 2 & 0,6283641 & 1,1 & 3 \\
\hline & Puntuación ámbito Económico & 2 & 0,5565923 & 1,6 & 3 \\
\hline & Puntuación ámbito Medio Ambiental & 2 & 0,6299044 & 1,05 & 3 \\
\hline & Puntuación ámbito Social & 2 & 0,7549418 & 0,5861 & 3 \\
\hline \multirow{7}{*}{ 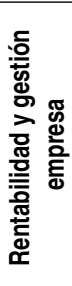 } & ROA -Rentabilidad Económica & 2 & 1 & 0,68 & 4,46 \\
\hline & ROE -Rentabilidad Financiera & 5 & 4 & 2,4 & 13,8 \\
\hline & Liquidez-Solvencia (C.R.) & 1 & 0,5214115 & 0,49 & 1,99 \\
\hline & Liquidez Inmediata (L.R.) & 1 & 0,5999917 & 0,23 & 1,83 \\
\hline & Margen Comercial & 1 & 0,8220401 & 0,34 & 2,22 \\
\hline & Aver Cost. (Gasto RRHHI $/ n^{\circ}$ empleados) & 28 & 21 & 2,99 & 52 \\
\hline & Profit per Employ (BAl $/ n^{\circ}$ empleados) & 8 & 8 & 0,49214 & 24 \\
\hline
\end{tabular}

FUENTE: Elaboración propia.

\section{Tabla 3. Correlaciones de variables RSE y rentabilidad de cooperativas del estudio}

\begin{tabular}{|c|c|c|c|c|c|c|c|c|c|c|c|}
\hline \multirow[b]{2}{*}{ Variables } & \multirow[b]{2}{*}{$\begin{array}{l}\text { Global } \\
\text { RSE }\end{array}$} & \multicolumn{3}{|c|}{$\begin{array}{l}\text { Puntuaciones ámbitos RSE } \\
\text { considerados }\end{array}$} & \multicolumn{2}{|c|}{ Rentabilidad } & \multicolumn{2}{|c|}{ Solvencia-liquidez } & \multirow{2}{*}{\begin{tabular}{|c|c}
$\begin{array}{c}\text { Margen } \\
\text { actividad }\end{array}$ \\
Margen \\
Comercial
\end{tabular}} & \multicolumn{2}{|c|}{$\begin{array}{l}\text { Costes y beneficios } \\
\text { sobre } N^{\circ} \text { empleados }\end{array}$} \\
\hline & & $\begin{array}{l}\text { Econó- } \\
\text { mica. }\end{array}$ & $\begin{array}{l}\text { Medio } \\
\text { Ambiental }\end{array}$ & Social & $\begin{array}{l}\text { ROA- } \\
\text { Eca. }\end{array}$ & $\begin{array}{l}\text { ROE- } \\
\text { Financ. }\end{array}$ & $\begin{array}{l}\text { Solvencia } \\
\text { (C.R.) }\end{array}$ & $\begin{array}{c}\text { Liquidez } \\
\text { Inmediata } \\
\text { (L.R.) }\end{array}$ & & $\begin{array}{c}\text { Aver Cost. } \\
\text { RRHH }\end{array}$ & $\begin{array}{c}\text { Profit } \\
\text { per. Empl. }\end{array}$ \\
\hline $\begin{array}{l}\text { Puntuación } \\
\text { Global RSE }\end{array}$ & 1 & & & & & & & & & & \\
\hline $\begin{array}{l}\text { Puntuación ámbito } \\
\text { Económico }\end{array}$ & 0,9499 & 1 & & & & & & & & & \\
\hline $\begin{array}{l}\text { Puntuación ámbito } \\
\text { Medioambiental }\end{array}$ & 0,9659 & 0,8514 & 1 & & & & & & & & \\
\hline $\begin{array}{l}\text { Puntuación ámbito } \\
\text { Social }\end{array}$ & 0,9908 & 0,9243 & 0,9498 & 1 & & & & & & & \\
\hline ROA -Rent. Eca. & 0,1766 & 0,3128 & $-0,0117$ & 0,2201 & 1 & & & & & & \\
\hline ROE -Rent. Finan. & 0,2329 & 0,3717 & 0,021 & 0,2899 & 0,9776 & 1 & & & & & \\
\hline Liquidez-Solv.C.R.) & $-0,1844$ & $-0,3757$ & 0,0578 & $-0,2318$ & $-0,6918$ & $-0,7976$ & 1 & & & & \\
\hline Liquidez Inm. (L.R.) & $-0,1251$ & $-0,2026$ & 0,0605 & $-0,2135$ & $-0,5816$ & $-0,7016$ & 0,9049 & 1 & & & \\
\hline Margen Comercial & 0,3177 & 0,2391 & 0,2415 & 0,4154 & 0,6156 & 0,6568 & $-0,262$ & $-0,3631$ & 1 & & \\
\hline $\begin{array}{l}\text { Aver Cost. (Gasto } \\
\text { RRHHH/n } n^{\circ} \text { empleados) }\end{array}$ & $-0,4046$ & $-0,4$ & $-0,264$ & $-0,4951$ & $-0,3135$ & $-0,4863$ & 0,529 & 0,5752 & $-0,7088$ & 1 & \\
\hline $\begin{array}{l}\text { Profit per Employ } \\
\text { (BAl/n } n^{\circ} \text { empleados) }\end{array}$ & 0,1001 & $-0,0655$ & 0,2469 & 0,0921 & $-0,2142$ & $-0,29$ & 0,7503 & 0,7243 & 0,3679 & 0,0237 & 1 \\
\hline
\end{tabular}

FUENTE: Elaboración propia. 


\section{Conclusiones y perspectivas de estudio}

En primer lugar, respecto al grado de desarrollo de comportamientos socialmente responsables, se puede concluir que el cumplimiento de las exigencias de RSE en las cooperativas analizadas (agroalimentarias y distribución comercial) ha sido bastante elevado, presentando valores medios altos y desviaciones muy homogéneas. Destaca que cuatro de ellas $(66,6 \%)$ se sitúan por encima del valor central.

Aunque la muestra es pequeña, dada la metodología aplicada de estudio de casos, se observa que la ordenación de las puntuaciones globales sobre el desarrollo de RSE no se corresponde en todos los casos de forma paralela con la posición relativa que ocupan en el mercado (tamaño e importancia de la cooperativa según el ranking), de forma que la tercera cooperativa de la muestra ocupa la primera posición en desarrollo de RSE. Esta característica podría avalar la coherencia y eficacia con que las cooperativas abordan el desarrollo real de la RSE en la configuración de sus relaciones con sus grupos de interés (Turker, 2009) de forma que no siempre un gran tamaño condiciona el grado de compromiso de la cooperativa con la RSE, sino que está más vinculado con los valores, filosofía de actuación y principios propios del movimiento cooperativo (Palomo y Valor, 2004; ACl, 1995; Castilla y Gallardo, 2014; Gallardo y Castilla, 2015). Adicionalmente estos resultados obtenidos en el periodo de crisis, avalarían en los casos analizados la teoría que justifica la relevancia de atender a los distintos componentes de RSE como elementos que favorecen una mayor resistencia de estas cooperativas ante la crisis (CICOPA, 2014a; Roelants, Dovgan, Eum y Terrasi, 2012). En los casos analizados, las cooperativas, por su propia naturaleza, asumen la responsabilidad social y empresarial desde los valores y principios de su identidad (Martínez, 2015), estando presentes en todos valores de RSE, especialmente los relacionados con la educación cooperativa, interoperación, el compromiso con la comunidad y la participación

En segundo lugar, partiendo de los modelos de RSE que reconocen su carácter multidimensional, la adopción de compromisos de RSE y su medición mediante indicadores, no presenta un desarrollo homogéneo y regular en los tres ámbitos considerados en el análisis, tal y como se refleja en los mapas gráficos y perfiles de RSE en las cooperativas analizadas. Esta observación denotaría determinados sesgos y deficiencias en la configuración de un modelo integral de RSE como verdadera estrategia empresarial, que podría tener limitaciones desde el punto de vista del coste los recursos empleados con estos fines en este tipo de organizaciones, así como cierta imposibilidad para delimitar y abarcar a todos los verdaderos grupos de interés de la cooperativa (Sanchís y Rodríguez, 2018). No obstante, cabe destacar que la cooperativa con una puntuación mayor presenta un desarrollo más compacto y uniforme de los factores de RSE, de forma que resulta más atractiva en relación a sus socios, clientes, proveedores y para la sociedad. De este modo, aunque la teoría predice un comportamiento previsible de las cooperativas en el desarrollo de los distintos ámbitos considerados de la RSE dada su naturaleza 
jurídica, la acción efectiva en estos aspectos dependerá del convencimiento que tenga cada entidad sobre el coste de su ejecución y los resultados derivados del mismo (Gallardo y Castilla, 2015), así como de las características particulares del sector donde operan, estando su aplicación condicionada a la operatividad e implantación según su contexto de actuación (Sanchís y Rodríguez, 2018).

Es preciso señalar que el estudio busca evaluar el grado en que las memorias, publicaciones e informaciones proporcionadas por las cooperativas son herramientas válidas que reflejan actuaciones y posicionamientos de RSE aplicables para el control interno y para la estrategia propia de las cooperativas. No obstante, no es objeto del trabajo evaluar la veracidad de los datos publicados, ni la implantación real de las políticas, procesos y acciones que las cooperativas identifican en sus informes. Se ha observado una relación positiva de aquellas cooperativas que publican memorias y anuarios de RSE, reflejada en la consecución de altas valoraciones en los compromisos de RSE, frente a las que solamente informan parcialmente de diferentes elementos y ámbitos de RSE. También se ha constatado la actuación parcial en alguno de los ámbitos de RSE (medioambiental, innovación...) por parte de las cooperativas analizadas, mediante la inclusión en catálogos de buenas prácticas en RSE, no coincidiendo en todos los casos con las puntuaciones globales más elevadas. Ello podría denotar respuestas parciales de las cooperativas de tipo comercial, ante presiones de los mercados donde operan y un entorno cada vez más competitivo, respondiendo de esta forma a una actuación en materia de RSE que valora las implicaciones de incorporar la RSE en su gestión y los resultados que pueden conseguir las empresas cooperativas (Gallardo y Vázquez, 2015). Consecuentemente, los valores de cooperativismo se verían identificados con la RSE, e integrados voluntariamente en cada caso analizado según el nivel de preocupación mostrado por estas entidades acerca de las cuestiones económicas, sociales, y medioambientales, en sus operaciones comerciales y en sus relaciones con sus grupos de interés (COCETA, 2010).

En tercer lugar, respecto a las relaciones observadas entre los comportamientos revelados como socialmente responsables en estas cooperativas y sus resultados económicos obtenidos en este periodo, los valores medios para el conjunto de las seis cooperativas estudiadas, reflejan algún tipo de concordancia entre un desarrollo global de la RSE y el margen comercial obtenido, relación que se ve incrementada en el caso del desarrollo de aspectos sociales. En términos de rentabilidad económica y financiera, se aprecia una mayor relación en el caso de actuaciones de RSE más relacionadas con el ámbito económico. Respecto a la utilización de la empresa de sus recursos humanos, la ratio de beneficio por empleado mantiene una relación positiva con el desarrollo global de la RSE en estas cooperativas, pero adquiere mayor relevancia con las actuaciones en materia de compromisos medioambientales de estas entidades. Ello podría relacionarse con la creación de valor económico para la cooperativa a partir de actuaciones o comportamientos socialmente responsables, planteando la gestión de los grupos de interés o stakeholders como un elemento clave para conseguir ventajas competitivas que permitan un crecimiento sostenido (Argandoña, 2011, Sanchís y Rodríguez, 2018), aunque este no es el único resultado, pues la RSE introduce elementos que posibilitan la creación de valor cooperativo, económico y no económico (Argandoña, 2010), de forma que todos los actores que participan en su generación puedan disfrutar del mismo (Melé, 2009). 
En cuanto al tipo de información analizada, en términos generales las cooperativas estudiadas parecen considerar la RSE como una ventaja competitiva, y asumen la obligación de ofrecer información no solo de datos económicos, sino también de otros indicadores como respuesta a las demandas en temas sociales y ambientales. El objetivo de dicha información es facilitar la evaluación de actuaciones en materia de RSE (intraevaluación) y la comparación entre diferentes cooperativas (interevaluación). La publicación de Memorias analizadas en la muestra de cooperativas, se convierte en un instrumento adecuado para la medición de la RSE, pues refleja una herramienta de transparencia y comunicación a la sociedad de estas actuaciones.

El estudio de casos planteado no pretende inferir resultados extrapolables desde el punto de vista estadístico (dado el tamaño de la muestra y la estructura de datos correspondiente a un solo periodo), sino una generalización interna dentro del grupo analizado (Jiménez y Comet, 2016). Consecuentemente, no se ha podido establecer una relación de causalidad en el sentido de que las prácticas de RSE en estas cooperativas lleven a obtener buenos resultados económicos o viceversa, aunque sí se observa una relación entre las variables de rentabilidad económica, financiera y solvencia con puntuaciones elevadas en el ámbito económico de la RSE, así como también entre el margen comercial y gasto por empleado con relación a puntuación alta en el global de RSE y en el ámbito social de la misma. En todo caso, este análisis de casos puede ser útil como punto de partida para tratar de incorporar herramientas que puedan servir de referencia entre los compromisos adquiridos de RSE por las cooperativas y los resultados conseguidos como empresa social.

Teniendo en cuenta lo anterior, como proyecto para futuras investigaciones en esta línea de cooperativas y RSE, se considera interesante contrastar las informaciones obtenidas a través de las publicaciones de Memorias con encuestas personalizadas, profundizando en la metodología de estudio de casos, e incrementar el periodo de análisis, y por otro lado, realizar estudios de corte empírico, ampliando el número de cooperativas y los sectores de actividad para lograr una muestra estadísticamente representativa que permita generalizar las conclusiones. Esto podría posibilitar comparaciones de cooperativas intrasectoriales, a la vez que con otras entidades de la Economía Social e incluso con empresas típicamente capitalistas, incluyendo en los análisis el componente del tamaño. 


\section{Referencias bibliográficas}

ASOCIACIÓN ESPAÑOLA DE CONTABILIDAD Y ADMINISTRACIÓN DE EMPRESAS (AECA) (2004): Marco Conceptual de la RSC, Documento AECA N ${ }^{\circ}$, Serie Responsabilidad Social Corporativa. AECA, Madrid.

ALIANZA COOPERATIVA INTERNACIONAL (ACI) (1995): Declaración de identidad cooperativa. Principios cooperativos, Manchester.

ALIANZA COOPERATIVA INTERNACIONAL (ACI) (2008): Informe de actividades, 2008. Recuperado 23 abril 2018 de: https://www.aciamericas.coop/IMG/pdf/INFORME_DE_ACTIVIDADES_2008.pdf.

ARAGÓN, C., ITURRIOZ, C. \& NARVAIZA, L. (2017): “Cooperatives' proactive social responsibility in crisis time: How to behave?", REVESCO, Revista de Estudios Cooperativos, 123, 7-36. DOI: 10.5209/REVE.53252.

ARCAS, N. y BRIONES, A.J. (2009): "Responsabilidad social empresarial de las organizaciones de la economía social. Valoración de la misma en la región de Murcia”, CIRIEC-España, Revista de Economía Pública, Social y Cooperativa, 65, 143-161.

ARGANDOÑA, A. (2010): "Don y gratitud en la empresa". En: D. Melé y J.M. Castellà (des.), "El desarrollo humano integral, Comentarios interdisciplinares a la Encícicla Caritas in veritate”, Barcelona: Editorial Iter, 227-441.

ARGANDOÑA, A. (2011): "La Teoría de Stakeholders y la creación de valor", Research paper DI-922, IESE Business School-Universidad de Navarra https://media.iese.edu/research/pdfs/DI-0922.pdf.

BAREA, J. (1990): "Concepto y agentes de la economía social en España", CIRIEC-España, Revista de Economía Pública, Social y Cooperativa, 8, 209-117.

BAREA, J. (1991): "La economía social en España", Revista de Economía y Sociología del Trabajo, 12, 8-16.

BAREA, J. y MONZÓN, J.L. (Dir.) (2002): La Economía social en España en el año 2000, Valencia: CIRIEC-España.

BARRERA, E. (2007): "La empresa social y su responsabilidad social”, Innovar, 17(30), 43-54.

BARRERA, J.J. (2016): "Transparencia y reputación como actitud y forma de ser de la empresa", CIRIEC-España, Revista de Economía Pública, Social y Cooperativa, 87, 327-350, doi:10.7203/ciriec-e.87.6860.

BEL, P. y MARÍN, S. (2008): "Criterios de eficiencia y buenas prácticas en los procesos de concentración de las organizaciones de participación", REVESCO, Revista de Estudios Cooperativos, 95, 9-43. 
BEL, P. y AUSIN, J.M. (2007): "Contribución de las sociedades cooperativas al desarrollo territorial", REVESCO, Revista de Estudios Cooperativos, 92, 41-71.

BRIO, J.A., FERNÁNDEZ, E. y JUNQUERA, B. (2005): "Dificultad de imitación de las capacidades medioambientales y ventaja competitiva: un estudio empírico", Revista Europea de Dirección y Economía de la Empresa, 14(4), 59-80.

BURKE, L. \& LOGSDON, J.M. (1996): "How corporate social responsibility pays off", Long Range Planning, 29(4), 495-502. DOl: 10.1016/0024-6301(96)00041-6.

CABALLER, V. (1982): "El comportamiento empresarial del agricultor en la dinámica de formación y desarrollo de cooperativas agrarias", Agricultura y Sociedad, 23, 193-216.

CABALLER, V., JULIÁ, J.F. y SEGURA, B. (1987): Gestión financiera de cooperativas agrarias, Valencia: Universidad Politécnica de Valencia.

CAMPOS, V. y CHAVES, R. (2012): "El papel de las cooperativas en la crisis agraria. Estudio empírico aplicado a la agricultura mediterránea española", Cuadernos de Desarrollo Rural, 9 (69), 175194.

CARRASCO, I. (2005): "La ética como eficiencia: la responsabilidad social en las cooperativas de crédito españolas", CIRIEC-España, Revista de Economía Pública, Social y Cooperativa, 53, 351367.

CARROLL, A.B. (1979): "A three-dimensional conceptual model of social performance", The Academy of Management Review, 4(4), 497-505. DOI: 10.5465/amr.1979.4498296.

CASTILLA, F. y GALLARDO, D. (2014): "La revelación social en sociedades cooperativas: una visión comparativa de las herramientas más utilizadas en la actualidad", REVESCO, Revista de Estudios Cooperativos, 114, 7-34. DOI: 10.5209/rev_REVE.2014.v114.44291.

CASTILLA, F., GALLARDO, D. y SÁNCHEZ, M.I. (2015): "La revelación social a partir de la Guía GRI de la economía social: una herramienta para mejorar las relaciones socio-cooperativa", CIRIECEspaña, Revista de Economía Pública, Social y Cooperativa, 83, 143-168.

CEBALLO, A.I. (2005): "Responsabilidad social: un valor añadido para las empresas, un criterio de discriminación positiva para los consumidores", CIRIEC-España, Revista de Economía Pública, Social y Cooperativa, 53, 65-77.

CEBREIRO, B. y FERNÁNDEZ, M.C. (2004): "Estudio de casos". En: F. Salvador Mata, J.L. Rodríguez Diéguez y A. Bolívar Botia, Diccionario enciclopédico de didáctica, Volumen 1, Málaga: Aljibe, 665-668.

CONFEDERACIÓN EMPRESARIAL ESPAÑOLA DE LA ECONOMÍA SOCIAL (CEPES) (2009): Anuario 2007-2008 de la Confederación Empresarial de la Economía Social, CEPES.

CONFEDERACIÓN EMPRESARIAL ESPAÑOLA DE LA ECONOMÍA SOCIAL (CEPES) (2011): Ranking de empresas relevantes de la economía social 2010-11, CEPES. 
CONFEDERACIÓN EMPRESARIAL ESPAÑOLA DE LA ECONOMÍA SOCIAL (CEPES) (2015): La economía social, otra forma de crear empleo. Propuestas de la Confederación Empresarial Española de la Economía Social a las Elecciones Generales, Madrid: CEPES.

CHAVES, R. (1997): "Economía políica de la economía social. Una revisión de la literatura económica reciente", CIRIEC-España, Revista de Economía Pública, Social y Cooperativa, 25, 141-162.

CHAVES, R. (1999): "La economía social como enfoque metodológico, como objeto de estudio y como disciplina científica”, CIRIEC-España, Revista de Economía Pública, Social y Cooperativa, 33, 115-139.

CHAVES, R. y MONZÓN, J.L. (2018): "La economía social ante los paradigmas económicos emergentes: innovación social, economía colaborativa, economía circular, responsabilidad social empresarial, economía del bien común, empresa social y economía solidaria", CIRIEC-España, Revista de Economía Pública, Social y Cooperativa, 93, 5-50. DOI: 10.7203/ciriec-e.93.12901.

CHAVES, R. y SOLER, F. (2004): El gobierno de las cooperativas de crédito en España, Valencia, España: CIRIEC-España.

CHUMACEIRO, A., HERNÁNDEZ, J., YORI, L. y ZIRITT, G. (2013): "Responsabilidad social empresarial y políticas públicas", Revista de Ciencias Sociales (Ve), XIX(2), 309-321.

CONFEDERACIÓN DE COOPERATIVAS DE TRABAJO ASOCIADO (COCETA) (2010): La RSE y las Cooperativas: evolución de las cooperativas que han aplicado políticas de RSE. Impactos y experiencias en un contexto de crisis económica. Recuperado 24 abril 2018 de: http://www.coceta.coop/publicaciones/rse-estudio-evolucion-cooperativas-politicas-rse.pdf.

CONFEDERACIÓN DE COOPERATIVAS DE TRABAJO ASOCIADO (COCETA) (2011): Gestión de la RSE. Modelo RSE COOP. Recuperado 15 mayo 2018 de: http://www.coceta.coop/publicaciones/rse-actualizacion-modelo-rsecoop.pdf.

CASASOLA, M. y SAAVEDRA, E.A. (2012): Economía Social: ejemplo privilegiado de Organizaciones Socialmente Responsables, Madrid: Cointegra y Ministerio de Empleo y Seguridad Social.

CASTRO, E. (2010): "El estudio de casos como metodología de investigación y su importancia en la dirección y administración de empresas", Revista Nacional de Administración, 1(2), 31-45. DOI: 10.22458/rna.v1i2.332.

COMISIÓN DE TRABAJO Y ASUNTOS SOCIALES (2006): Informe de la subcomisión para potenciar y promover la responsabilidad social de las empresas. Libro Blanco de la RSC. BOCG núm. 424, de 24 de agosto de 2006.

COMISIÓN ESPECIAL PARA EL ESTUDIO DE UN CÓDIGO ÉTICO DE LOS CONSEJOS DE ADMINISTRACIÓN DE LAS SOCIEDADES (1998): El gobierno de las sociedades cotizadas (Informe Olivencia), Madrid: Ministerio de Economía y Hacienda. 
COMISIÓN ESPECIAL PARA EL FOMENTO DE LA TRANSPARENCIA Y LA SEGURIDAD EN LOS MERCADOS Y LAS SOCIEDADES COTIZADAS (Código Aldama) (2003): Informe de la comisión especial para el fomento de la transparencia y la seguridad en los mercados y en las sociedades cotizadas, Madrid, 8 de enero, Comisión Nacional del Mercado de Valores.

COMISIÓN EUROPEA (2001): Libro Verde. Fomentar un marco europeo para la responsabilidad social en las empresas, COM (2001), 366 final. Bruselas: Comisión Europea.

COMISIÓN EUROPEA (2011): Estrategia renovada de la UE para 2011-2014 sobre la responsabilidad social de las empresas, COM (2011) 681 final, Bruselas: Comisión Europea.

COQUE, J. (2008): "Puntos fuertes y débiles de las cooperativas desde un concepto amplio de gobierno empresarial", REVESCO, Revista de Estudios Cooperativos, 95, 65-93.

DE CASTRO, M. (2005): "La responsabilidad social de las empresas, o un nuevo concepto de empresa", CIREC-España, Revista de Economía Pública, Social y Cooperativa, 53, 29-51.

DE LA CUESTA, M. (2005): "La responsabilidad social corporativa o responsabilidad social de la empresa", Jornadas de economía alternativa y solidaria, Bilbao, España.

DE QUEVEDO, E., DE LA FUENTE, J.M. y DELGADO, J.B. (2005): "Reputación corporativa y creación de valor. Marco teórico de una relación circular", Investigaciones Europeas de Dirección y Economía de la Empresa, 11(2), 81-97.

EISENHARDT, K.M. (1989): "Building theories form case study research", Academy of Management Review, 14(4), 532-550. DOl: 10.5465/amr.1989.4308385.

ESCUELA DE ECONOMÍA SOCIAL (2012): Estudio de la responsabilidad social en las empresas de economía social de Andalucía. Recuperado 15 marzo 2018 de: https://www.escueladeeconomiasocial.es/comunicacion/estudio-de-la-rse-en-la-economia-social-de-andalucia.

FAJARDO, G. (2018): "La identificación de las empresas de economía social en España. Problemática jurídica", REVESCO, Revista de Estudios Cooperativos, 99-126. DOI: 10.5209/reve.60209.

FAURA, I. y MONZÓN, J.L. (Dirs.) (1999): Memoria CEPES-CIRIEC de la Economía social 1998, Valencia: CIRIEC-España.

FERNÁNDEZ, J.L. y BAJO, A. (2012): "La teoría del stakeholders o de los grupos de interés, pieza clave de la RSE, del éxito empresarial y de la sostenibilidad", Revista Internacional de investigación en Comunicación aDResearch ESIC, 6(6), 130-143. DOI: 10.7263/ADR.RSC.006.07.

FORÉTICA (2008): Informe Forética 2008. Evolución de la responsabilidad social de las empresas en España. Recuperado 10 noviembre 2018 de: https://mouriz.files.wordpress.com/2008/11/informeforetica-2008.pdf

FORÉTICA (2011): Informe Forética 2010. Evolución de la responsabilidad social de las empresas en España. Recuperado 10 noviembre 2018 de: https://foretica.org/wp-content/uploads/publicaciones/informes-foretica/informe_2011_version_extendida.pdf. 
FREEMAN, R.E. (1984): Strategic management: A stakeholder approach, Pitman - Ballinger, Boston.

FRIEDMAN, M. (1970): "The social responsibility of business is to increase its profits", New York Times Magazine, September, page SM17.

GALLARDO, D. y CASTILLA, F. (2015): "Modelo de gestión para la responsabilidad social en cooperativas", Economía Industrial, 396, 139-149.

GARCÍA-GUTIÉRREZ FERNÁNDEZ, C. (1992): "Precisiones acerca de algunos tópicos confusos sobre la sociedad cooperativa". En: Tampori Serviendum, Santiago de Compostela.

GARRIGA, E. \& MELÉ, D. (2004): "Corporate social responsibility theories: Mapping the territory", Journal of Business Ethics, 53(1-2), 51-71. doi:10.1023/b:busi.0000039399.90587.34

GÓMEZ-LIMON, J., CASQUET, E. y ATANCE, I. (2003): "Análisis económico-financiero de las cooperativas agrarias en Castilla y León”, CIRIEC-España, Revista de Economía Pública, Social y Cooperativa, 46, 151-189.

GUI, B. (1991): "The economic rationale for the third sector. Nonprofit and other noncapitalist organizations", Annals of Public and Cooperative Economics, 62(4), 551-572.

HUSTED, B.W. \& ALLEN, D.B. (2000): "Is it ethical to use ethics as strategy?", Journal of Business Ethics, 27(1-2), 21-31. DOI: 10.1023/A:1006422704548.

HUSTED, B. \& J. JESUS (2006): "Taking Friedman seriously: Maximizing profits and social performance", Journal of Management Studies, 43(1), 75-91. DOI: 10.1111/j.1467-6486.2006.00583.x.

ITURRIOZ, J. y DOPACIO, C. (2009): "La responsabilidad social en las sociedades cooperativas: una perspectiva económico financiera", Cuadernos de Estudios Empresariales, 19, 153-173.

JÁUREGUI ANTONDO, R. (2005): "La empresa responsable en la nueva sociedad", Revista Economistas, 106, 46-52.

JIMÉNEZ, V.E. y COMET, C. (2016): "Los estudios de casos como enfoque metodológico", ACADEMO Revista de Investigación en Ciencias Sociales y Humanidades, 3(2), 1-11.

JULIÁ, J. \& MELIÁ, E. (2008): "Social economy and de cooperative movement in Europe: input to a new vision of agriculture and rural development in the Europe of the 25", CIRIEC-España, Revista de Economía Pública, Social y Cooperativa, 62, 147-172.

LEROUX, M.F. (2012): "Las cooperativas demuestran su mayor resistencia ante la crisis", Cumbre Internacional de las Cooperativas, Quebec.

LEY 2/2011, de 4 de marzo, de Economía Sostenible. BOE núm. 55, de 5 de marzo de 2011.

LEY 5/2011, de 29 de marzo, de Economía Social. BOE núm. 76, de 30 de marzo de 2011.

LIGER, Q., STEFAN, M. \& BRITTON, J. (2016): Social economy. Study for the IMCO, Committee Policy Department A: Economic and Scientific Policy, Bruselas: European Parliament. 
LINZ, R.A. (1996): "A Resource-Based-View of the socially responsible firm: Stakeholder interdependence, ethical awareness, and issue responsiveness as strategic assets", Journal of Business Ethics, 15, 1355-1363. DOI: 10.1007/bf00411820.

LÓPEZ, A. \& MARCUELLO, C. (2006): "Agricultural cooperatives and economic efficiency", New Medit, 3, 119-22.

LÓPEZ, M., NAVARRO, A., LÓPEZ, F., CABA, M.C. (2005): Control económico en las cooperativas: propuesta de un modelo basado en indicadores, Almería: Universidad de Almería.

LOZANO. J., ALBAREDA, L. y YSA, T. (2005): “¿Qué pueden hacer los gobiernos para promover la Responsabilidad Social de la Empresa (RSE)?”, CIRIEC-España, Revista de Economía Pública, Social y Cooperativa, 53, 53-64.

MARTÍN, M.A. y VIDAL, F. (2001): "Análisis comparativo de las bodegas cooperativas inscritas en las Denominaciones de Origen vínicas de la Comunidad Valenciana", Esic Market, 110, 143-167.

MARTíNEZ, A. (2015): "Las cooperativas y su acción sobre la sociedad", REVESCO, Revista de Estudios Cooperativos, 117, 34-49. DOI: 10.5209/rev_reve.2015.v117.48144.

MARTíNEZ, R. y MARTÍNEZ, D. (2016): "Perspectivas de la sustentabilidad: Teoría y campos de análisis", Pensamiento Actual, 16(26), 123-145.

MELÉ, D. (2009): "The view and purpose of the firm in Freeman's stakeholders theory", Philosophy of Management, 8, 3-13.

MELIÁN, A. (2006): "Una aproximación a los instrumentos de medición de la responsabilidad social empresarial (RSE) en las cooperativas de crédito". En: XI Jornadas de Investigadores de Economía Social y Cooperativa Santiago de Compostela: CIRIEC-España y CECOOP.

MINISTERIO DE TRABAJO, MIGRACIONES Y SEGURIDAD SOCIAL (MEYSS) (2014): Estrategia Española de Responsabilidad Social de las Empresas. Recuperado 20 marzo 2018 de: http://www.mitramiss.gob.es/es/rse/eerse/index.htm.

MINISTERIO DE TRABAJO Y ASUNTOS SOCIALES (MTAS) (2007): Informe del foro de Expertos en Responsabilidad Social de la Empresas. En: https://observatoriorsc.org/wpcontent/uploads/2013/07/foroexpertos_rse_informe.pdf. Con acceso 19/12/2018.

MONTEGUT, Y., SABATÉ, P. y CLOP, M.M. (2002): "Análisis económico-financiero de las cooperativas agrarias productoras de aceite de oliva de la DO. Garrigues", Investigación agraria. Producción y protección vegetal, 17 (3), 423-440.

MONTEGUT, Y. y CRISTÓBAL, F. (2012): "Análisis interno de las cooperativas agroalimentarias catalanas desde una perspectiva comparada: los sectores del aceite y la fruta dulce", REVESCO, Revista de Estudios Cooperativos, 108, 113-151. DOI: 10.5209/rev_reve.2012.v18.39587.

MONZÓN, J.L. y ANTUÑANO, I. (2012): Veinte casos de cooperativas socialmente responsables, Valencia: CIRIEC-España. 
MORENO, J.A. (2004): "Responsabilidad social corporativa y competitividad: una visión desde la empresa", RVEH-Revista Valenciana de Economía y Hacienda, 12(III), 10-49.

MOYANO, J. y FIDALGO, F.A. (2001): "El impacto de la dimensión en la sociedad cooperativa agraria. Una aplicación al cooperativismo oleícola", REVESCO, Revista de Estudios Cooperativos, 73, 95-121.

MOZAS, A. y BERNAL, E. (2006): "Desarrollo territorial y economía social", CIREC-España, Revista de Economía Pública, Social y Cooperativa, 55, 125-140.

MOZAS, A. y PUENTES, R. (2010): "La responsabilidad social corporativa y su paralelismo con las sociedades cooperativas", REVESCO, Revista de Estudios Cooperativos, 103, 75-100.

MUGARRA, A. (2001): "Responsabilidad y balance social hoy en día: un reto para las cooperativas", CIRIEC-España, Revista de Economía Pública, Social y Cooperativa, 39, 25-50.

MUKHERJEE, S. \& PYNE, S. (2016): "Cooperatives as alternative form of organization for CSR effectiveness: Insights from Rabindranath Tagore", Global Business Review, 17(6), 1497-1509. doi:10.1177/0972150916660445.

NACHAR, P. (2013): Sociedades cooperativas. Una aproximación desde la responsabilidad social corporativa y el desarrolo, Tesis doctoral, Zaragoza, España, Universidad de Zaragoza.

NILSSON, J. (1996): "The nature of cooperative values and principles", Annals of Public and Cooperative Economics, 67(4), 633-653. DOI: 10.1111/j.1467-8292.1996.tb01411.x.

OBSERVATORIO DE RESPONSABILIDAD SOCIAL CORPORATIVA (2012): ¿Qué es RSC?. Recuperado 10 enero 2018 de: https://observatoriorsc.org/la-rsc-que-es/

OBSERVATORIO DE LA RESPONSABILIDAD CORPORATIVA (2014): Las políticas públicas en torno a la responsabilidad social corporativa, Recuperado 17 julio 2018 de: https://observatoriorsc.org/inicio/que-hacemos/publicaciones/.

OBSERVATORIO DE LA RESPONSABILIDAD CORPORATIVA (2015): La Responsabilidad Social Corporativa y su implicación en la gobernanza empresarial, Recuperado 17 julio 2018 de: https://observatoriorsc.org/inicio/que-hacemos/publicaciones/.

ORGANIZACIÓN INTERNACIONAL DE COOPERATIVAS EN LA INDUSTRIA Y LOS SERVICIOS (CICOPA) (2014a): Cooperativas y empleo: Un informe mundial. Recuperado de: http://www.relats.org/documentos/ESS.CICOPA2.pdf (30/10/2018).

ORGANIZACIÓN INTERNACIONAL DE COOPERATIVAS EN LA INDUSTRIA Y LOS SERVICIOS (CICOPA) (2014b): Las cooperativas como constructoras del desarrollo sostenible. Recuperado de 3 julio 2017:

https://latin.weeffect.org/app/uploads/2018/09/las_cooperativas_como_constructoras_de_desarr ollo_sostenible_es_cicopaweb.pdf 
ORGANIZACIÓN PARA LA COOPERACIÓN Y DESARROLLO ECONÓMICO (OCDE) (2015): G20/OECD Principles of Corporate Governance, Paris: OECD Publishing. DOI: http://dx.doi. org/10.1787/9789264236882-en.

PALADINO, M. y MOHAN, A. (2002): "Tendencias de la responsabilidad social empresaria en Argentina", Documento de Investigación. Escuela de Dirección de Negocios. Universidad Austral, 2-17.

PALOMO, R.J. y VALOR, C. (2004): "El 'activismo' de los socios como catalizador de la responsabilidad social de la empresa: aplicación a las organizaciones de participación", CIRIEC-España, Revista de Economía Pública, Social y Cooperativa, 50, 167-190.

PEDREÑO, J.A. (2009): "Las empresas de Economía Social en el escenario socioeconómico". En: Anuario de la Economía Social 2007-2008, Madrid: CEPES, 7-10.

PÉREZ, F.J., ESTEBAN, L. y GARGALLO, A. (2009): "Participación, gobierno democrático y resultados cooperativos: una perspectiva de RSE", CIRIEC-España, Revista de Economía Pública, Social y Cooperativa, 65, 2009, 163-190.

PORTER, M.E. \& KRAMER, M.R. (2002): "The Competitive Advantage of Corporate Philanthropy", Harvard Business Review, 80(12), 56-69.

PRAHALAD, C.K. (2002): "Strategies for the bottom of the economic pyramid: India as a source of innovation", Reflections: TheSOL Journal, 3(4), 6-17.

PRAHALAD, C.K. \& HAMMOND, A. (2002): "Serving the world's poor, profitably", Harvard Business Review, 80, 45-88.

QUEVEDO, E. (2003): Reputación y creación de valor, Madrid: Thomson.

ROELANTS, B., DOVGAN, D. EUM, H. \& TERRASI, E. (2012): The resilience of the cooperative model, Bruselas: CECOP-CICOPA Europe.

RSECOOP (2007): Responsabilitat Social de les empreses en l'economía cooperativa. Herramienta de RSE para la economía social, Guía GRI para elaborar la memoria de sotenibilidad.URL. Recuperado de: http://www.rsecoop.coop/esp.

RSECOOP (2011): Gestión de la RSE. Nuevo modelo de RSE COOP. Recuperado 15 mayo 2018 de: http://www.coceta.coop/publicaciones/rse-actualizacion-modelo-rsecoop.pdf.

RUIZ, M.A., HERNÁNDEZ, M.J. y GARCÍA, E. (2006): "Estado actual de la investigación sobre sociedades cooperativas agrarias en España", CIRIEC-España, Revista de Economía Pública, Social y Cooperativa, 56, 65-86.

RYAN, B., SCAPENS, R. y THEOBALD, M. (2004): Metodología de la investigación en finanzas y contabilidad, Barcelona, España: Ediciones Deusto.

SANCHIS, J.R. y RODRIGUEZ, S. (2018): "Responsabilidad Social en banca. Su aplicación al caso de la banca cooperativa", REVESCO, Revista de Estudios Cooperativos, 127, 204-227. DOI: 10.5209/REVE.59771. 
SAJARDO, A. (1998): El sector no lucrativo en el ámbito de los servicios sociales de la Comunidad Valenciana, Valencia: CIRIEC-España.

SAJARDO-MORENO, A. y CHAVES-SAJARDO, R.J. (2017): "Responsabilidad Social en las empresas de Economía Social: un análisis comparativo del tejido productivo en la Comunidad Valenciana", REVESCO, Revista de Estudios Cooperativos, 125, 213-242. DOI: 10.5209/reve.57065.

SEGUÍ, E., SEGUÍ, D., SARASA, C. y BAVIERA, A. (2012): "La comunicación de las políticas de RSC en las cooperativas de crédito: análisis a través del estudio del caso", Sociedad y Utopía. Revista de Ciencias Sociales, 40, 383-402.

SEGURA B. y OLTRA M.J. (2005): "Eficiencia en la gestión de las cooperativas agrarias de Comercialización”, Investigación Agraria. Economía, 10(2), 217-232.

SERVER, R. y CAPÓ, J. (2009): "La responsabilidad empresarial en un contexto de crisis. Repercusión en las sociedades cooperativas", CIRIEC-España, Revista de Economía Pública, Social y Cooperativa, 65, 7-31.

SERVER, R.J. y SEGURA, B. (1990): "Situación económico financiera de las organizaciones de productorcascases de frutas y hortalizas (OPFH) en la Comunidad Valenciana", Investigación Agraria. Economía, 5(1), 19-36.

SERVER, R. y VILLALONGA, I. (2005): "La responsabilidad social corporativa y su gestión integrada", CIRIEC-España, Revista de Economía Pública, Social y Cooperativa, 53, 137-161.

SIMANCAS, M. y LEDESMA, O. (2017): "El papel de los stakeholders en los procesos de gobernanza y renovación de las áreas turísticas de litoral", Estudios y Perspectivas en Turismo, 26 (201), 348369.

SPEAR, R., DEFOURNY, J., FAVREAU, L. \& LAVILLE, J.L. (eds) (2001): Tackling social exclusion in Europe. The contribution of the social economy, Aldershot: Ashgate Publishing Ltd.

STAKE, R.E. (2005): Investigación con estudio de casos, Madrid: Morata.

TORO, D. (2006): "El enfoque estratégico de la responsabilidad social corporativa: revisión de la literatura académica", Intangible Capital, 2(4), 338-358.

TURKER, D. (2009): "Measuring corporate social responsibility: A scale development study", Journal of Business Ethics, 85 (4), 411-420.

VARGAS, A. y VACA, R. (2005): "Responsabilidad social y cooperativismo: Vínculos y potencialidades", CIRIEC-España, Revista de Economía Pública, Social y Cooperativa, 53, 241-260.

VÁZQUEZ, O. (2015): "Factores que influyen en la calidad y cantidad de responsabilidad social en las empresas españolas. Estudio de caso de las empresas del Ibex 35", CIRIEC-España, Revista de Economía Pública, Social y Cooperativa, 85, 181-215. DOI: 10.7203/ciriec-e.85.6912. 
VERGARA. C.A. y ORTÍZ, D. (2016): "Desarrollo sostenible: enfoques desde las ciencias económicas", Apuntes Cenes, 35(62), 15-52.

VIDAL, F., SEGURA, B. y RAYOS, J.A. (2001): "Situación económico-financiera de las sociedades agrarias de transformación (SAT) de comercialización hortofrutícola de la provincia de Alicante", Investigación Agraria, 16(1), 71-86.

VILLARREAL, O. y LANDETA, J. (2010): "El estudio de casos como metodología de investigación científica en dirección y economía de la empresa. Una aplicación a la internacionalización", Investigaciones Europeas de Dirección y Economía de la Empresa, 16(3), 31-52. DOl: 10.1016/S1135-2523(12)60033-1.

WOOD, D. (1991): "Corporate social performance revisited", The Academy of Management Review, 16(4), 691-718.

YIN, R.K. (1989): Case study research: Design and methods. Applied Social Research Methods. Series 5, London: Sage Publications.

\section{Anexo. Elementos considerados en la evaluación: Factores relevantes de RSE}

\begin{tabular}{|c|c|c|c|}
\hline 옹 & \multicolumn{3}{|c|}{$\begin{array}{l}\text { Compromiso } \\
\text { de RSE Pregunta con escala de graduación }(0,1,2,3) \text {. }\end{array}$} \\
\hline \multirow[t]{3}{*}{ 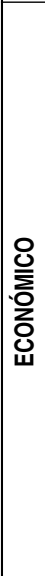 } & 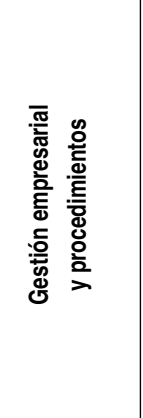 & $\begin{array}{l}\text { GESTIÓN EMPRESARIAL } \\
\text { 1. Explicita: Misión, Visión, Valores y Objetivos estratégicos } \\
\text { 2. En la Misión y Visión se incluyen consideraciones } \\
\text { sobre RSE } \\
\text { 3. Indicadores sobre el proceso de consecución de objetivos } \\
\text { 4. Participación distintos niveles redacción de Misión } \\
\text { y Valores } \\
\text { 5. Se hacen consultas externas (proveedores, clientes, } \\
\text { comunidad.) en la redacción de la Misión y Valores } \\
\text { 6. Revisa periódicamente Misión y Valores de la cooperativa } \\
\text { 7. Difunde públicamente (web, publicaciones) Misión y Valores }\end{array}$ & $\begin{array}{l}\text { CÓDIGOS Y PROCEDIMIENTOS } \\
\text { 8. La cooperativa dispone de códigos } \\
\text { de Ética y Conducta formales } \\
\text { 9. Normas internas que prohíben prácticas } \\
\text { discriminatorias en la cooperativa } \\
\text { 10. La cooperativa cumple con la legislación } \\
\text { impositiva y de Seguridad Social vigente } \\
\text { 11. Redacta anualmente una Memoria o Informe } \\
\text { 12. La Memoria hace referencia a actividades } \\
\text { de RSE }\end{array}$ \\
\hline & $\begin{array}{l}\text { Uso recursos } \\
\text { locales }\end{array}$ & $\begin{array}{l}\text { 13. \% compras producidas en el territorio sobre total } \\
\text { compras }\end{array}$ & $\begin{array}{l}\text { 14. Valor económico retenido en el territorio } \\
\text { según compromisos adquiridos }\end{array}$ \\
\hline & $\begin{array}{l}\text { Sistema } \\
\text { gestión }\end{array}$ & $\begin{array}{l}\text { 15. Existencia de un sistema de gestión de calidad } \\
\text { documentado }\end{array}$ & $\begin{array}{l}\text { 16. Integración de RSE en el sistema de } \\
\text { gestión }\end{array}$ \\
\hline
\end{tabular}




\begin{tabular}{|c|c|c|}
\hline \multirow[t]{2}{*}{ 엄 } & 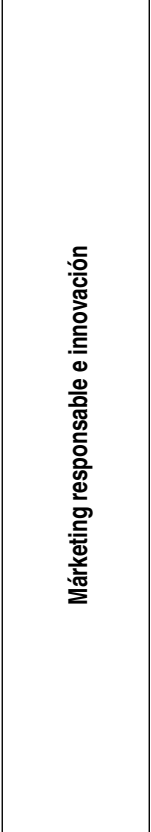 & $\begin{array}{l}\text { PLAN DE MARKETING Y RSE } \\
\text { 17. Existe un Plan de Marketing con un sistema de comunicación externa } \\
\text { 18. Esta incorporada la Responsabilidad Social en el plan de Marketing } \\
\text { OPINION DE CLIENTES } \\
\text { 19. Tiene un procedimiento para conocer el nivel de satisfacción de sus clientes } \\
\text { 20. Tiene un departamento o responsable de atención a los clientes } \\
\text { PROCESO DE RECLAMACIONES } \\
\text { 21. Reclamaciones: tiene un sistema de reclamaciones ágil y con difusión } \\
\text { 22. La empresa evalúa anualmente el número de reclamaciones } \\
\text { RELACIONES CON LA CADENA DE PROVEEDORES } \\
\text { 23. Posee un plan anual de consulta de satisfacción con los proveedores } \\
\text { INVESTIGACIÓN Y DESARROLLO } \\
\text { 24. Búsqueda continua de perfeccionamiento de productos y servicio: más seguros y con menor riesgo } \\
\text { para consumidores } \\
\text { MARKETING Y COMUNICACIÓN } \\
\text { 25. Existe transparencia en la información al público consumidor de los posibles riesgos de los productos } \\
\text { o servicios que ofrece la empresa (uso irresponsable o excesivo, etc.) } \\
\text { 26. Especificaciones, precios y condiciones de comercialización claras y coinciden con producto o servicio } \\
\text { ofrecido } \\
\text { 27. La cooperativa promueve prácticas de ventas con criterios éticos } \\
\text { INNOVACIÓN } \\
\text { 28. Recursos destinados a la innovación }\end{array}$ \\
\hline & 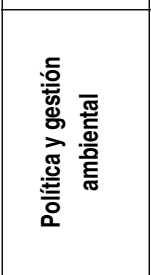 & $\begin{array}{l}\text { 29. Existencia de sanciones y multas por incumplimiento de legislación ambiental } \\
\text { 30. Conocimiento y documentación de impactos medioambientales anuales derivados de las actividades } \\
\text { EL MEDIO AMBIENTE COMO COMPROMISO EMPRESARIAL } \\
\text { 31. La cooperativa dispone de procesos de capacitación en temas medioambientales } \\
\text { 32. Genera o participa en alianzas con otras organizaciones desarrollando acciones en favor del cuidado } \\
\text { medioambiental } \\
\text { 33. Se consideran aspectos ambientales al seleccionar proveedores }\end{array}$ \\
\hline \multirow[t]{3}{*}{ 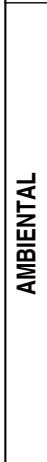 } & 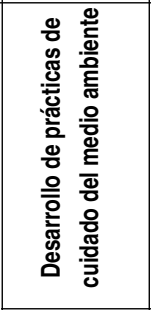 & $\begin{array}{l}\text { 34. Se promueve el reciclado de insumos y otros productos } \\
\text { 35. Sistema de retorno de envases, embalajes, productos obsoletos, etc. generados por la propia empresa } \\
\text { 36. Se dispone de una política tendiente al uso de combustibles/energías menos contaminantes } \\
\text { 37. Se busca minimizar la liberación a la atmósfera de gases nocivos para la capa de ozono (CFC,... etc.) } \\
\text { 38. Se procura disminuir al máximo la utilización de productos tóxicos en la empresa } \\
\text { 39. Se promueve la reducción en el consumo de energía y agua } \\
\text { 40. Implementa procesos para el destino adecuado de los residuos generados por la actividad específica } \\
\text { 41. Implementa procesos para el destino o reciclado de "otros" residuos generados en la empresa }\end{array}$ \\
\hline & $\begin{array}{l}\text { Impacto } \\
\text { ambiental }\end{array}$ & $\begin{array}{l}\text { 42. Se dispone de controles del impacto ambiental generado por sus actividades } \\
\text { 43. La cooperativa tiene la política de atender quejas y/o denuncias referidas a la agresión al medio ambiente }\end{array}$ \\
\hline & \begin{tabular}{|l|} 
Integración \\
en el entorno
\end{tabular} & $\begin{array}{l}\text { 44. Medidas adoptadas para colaborar en la preservación y/o restauración de los espacios naturales } \\
\text { próximos }\end{array}$ \\
\hline
\end{tabular}




\begin{tabular}{|c|c|c|}
\hline \multirow{12}{*}{ 这 } & $\begin{array}{l}\text { Democracia } \\
\text { Interna }\end{array}$ & $\begin{array}{l}\text { 45. Requisitos de entrada y salida en la cooperativa } \\
\text { 46. Participación real en los órganos de decisión cooperativa } \\
\text { 47. Información a miembros socios/as de la cooperativa }\end{array}$ \\
\hline & $\begin{array}{l}\text { Diálogo y } \\
\text { transparencia } \\
\text { grupos interés }\end{array}$ & $\begin{array}{l}\text { 48. Identificación de los grupos de interés } \\
\text { 49. Relación con los grupos de interés } \\
\text { 50. Valoración de la satisfacción de los grupos de interés }\end{array}$ \\
\hline & Formación & $\begin{array}{l}\text { 51. Formación en la plantilla } \\
\text { 52. Formación en Economía Social }\end{array}$ \\
\hline & $\begin{array}{l}\text { Igualdad de } \\
\text { oportunidad }\end{array}$ & $\begin{array}{l}\text { 53. Política de igualdad de oportunidades } \\
\text { 54. Diferencia salarial entre sexos }\end{array}$ \\
\hline & $\begin{array}{l}\text { Seguridad e } \\
\text { higiene en } \\
\text { el trabajo }\end{array}$ & $\begin{array}{l}\text { 55. La cooperativa tiene programa de prevención de accidentes de trabajo y enfermedades profesionales } \\
\text { 56. Preocupación por mejorar las condiciones de trabajo más allá de las exigencias legales } \\
\text { 57. Media de permanencia en la cooperativa / Política de retención }\end{array}$ \\
\hline & $\begin{array}{l}\text { Condiciones } \\
\text { socio- } \\
\text { laborales }\end{array}$ & $\begin{array}{l}\text { 58. Diferencias salariales en la cooperativa } \\
\text { 59. Prestaciones sociales } \\
\text { 60. Representación de los empleados y empleadas } \\
\text { 61. Existen componentes de participación en los resultados } \\
\text { 62. Existe transparencia en la información (financiera, producción, estrategias) }\end{array}$ \\
\hline & $\begin{array}{l}\text { Conciliación } \\
\text { vida personal } \\
\text { y laboral }\end{array}$ & $\begin{array}{l}\text { 63. Medidas de conciliación } \\
\text { 64. La cooperativa desarrolla actividades sociales para trabajadores y familiares }\end{array}$ \\
\hline & $\begin{array}{l}\text { Satisfacción } \\
\text { de clientes }\end{array}$ & 65. Valoración de la satisfacción de los clientes \\
\hline & $\begin{array}{l}\text { Inter- } \\
\text { cooperación }\end{array}$ & $\begin{array}{l}\text { 66. Actividades de cooperación (acciones o programas) } \\
\text { 67. Participación en asociaciones sectoriales }\end{array}$ \\
\hline & $\begin{array}{l}\text { Comunidad } \\
\text { local }\end{array}$ & $\begin{array}{l}\text { 68. Patrocinio y acción social en la comunidad (Política de apoyo a la comunidad) } \\
\text { 69. Promueve integración de personas con capacidades diferentes en la cooperativa } \\
\text { 70. Mejora impactos en comunidad más allá de la regulación existente (ruidos, olores, movimientos de } \\
\text { vehículos...) } \\
\text { 71. Posee un programa de voluntariado corporativo } \\
\text { 72. Inversiones socialmente responsables }\end{array}$ \\
\hline & $\begin{array}{l}\text { Empresas } \\
\text { proveedoras } \\
\text { y contratadas }\end{array}$ & 73. Empresas homologadas: criterios ambientales y sociales en compra y contratación \\
\hline & Competencia & 74. Competencia leal de la cooperativa \\
\hline
\end{tabular}

FUENTE: Elaboración propia a partir de RSE.COOP, 2007. 